\title{
Ergative Case and the Transitive Subject: A View from Nez Perce
}

\section{Citation}

Deal, Amy Rose. 2010. Ergative case and the transitive subject: A view from Nez Perce. Natural Language and Linguistic Theory 28(1): 73-120.

\section{Published Version}

doi:10.1007/s11049-009-9081-5

\section{Permanent link}

http://nrs.harvard.edu/urn-3:HUL.InstRepos:4263737

\section{Terms of Use}

This article was downloaded from Harvard University's DASH repository, and is made available under the terms and conditions applicable to Other Posted Material, as set forth at http:// nrs.harvard.edu/urn-3:HUL.InstRepos:dash.current.terms-of-use\#LAA

\section{Share Your Story}

The Harvard community has made this article openly available.

Please share how this access benefits you. Submit a story.

\section{Accessibility}


Natural Language and Linguistic Theory manuscript No.

(will be inserted by the editor)

\title{
Ergative case and the transitive subject: a view from Nez Perce
}

\author{
Amy Rose Deal
}

March 22, 2009

\begin{abstract}
Ergative case, the special case of transitive subjects, raises questions not only for the theory of case but also for theories of subjecthood and transitivity. This paper analyzes the case system of Nez Perce, a "three-way ergative" language, with an eye towards a formalization of the category of transitive subject. I show that it is object agreement that is determinative of transitivity, and hence of ergative case, in Nez Perce. I further show that the transitivity condition on ergative case must be coupled with a criterion of subjecthood that makes reference to participation in subject agreement, not just to origin in a high argument-structural position. These two results suggest a formalization of the transitive subject as that argument uniquely accessing both high and low agreement information, the former through its (agreement-derived) connection with $\mathrm{T}$ and the latter through its origin in the specifier of a head associated with object agreement (v). In view of these findings, I argue that ergative case morphology should be analyzed not as the expression of a syntactic primitive but as the morphological spell-out of subject agreement and object agreement on a nominal.
\end{abstract}

Keywords Nez Perce $\cdot$ ergativity $\cdot$ transitivity $\cdot$ case $\cdot$ agreement $\cdot$ anaphor agreement effect $\cdot$ Sahaptin

\section{The category of transitive subject}

An analysis of ergative case, the special case of transitive subjects, can only be as adequate as the theories of subjecthood and transitivity on which it rests. The lack of a complete and satisfying formal analysis of ergative case cannot be independent of the relatively meager attention afforded the study of transitivity within generative grammar, and lack of integration of what is known about transitivity with what is

Department of Linguistics, University of Massachusetts Amherst, 226 South College, Amherst MA 01003

E-mail: amyrose@ linguist.umass.edu 
known about subjecthood. This paper analyzes the case system of Nez Perce (Niimiipuutímt), which shows a "three-way ergative" pattern, with an eye towards a formalization of the category of transitive subject. ${ }^{1}$ Nez Perce provides a clear example of a language for which a non-trivial transitivity criterion is required, as it treats both one-argument clauses and certain two-argument clauses as intransitive in the sense relevant to ergative case. It also shows the importance of an appropriate criterion of subjecthood, as ergative appears on subjects from a variety of theta-roles and yet is importantly syntactically constrained. An explanatory analysis of ergativity in a particular language can only be produced once we can formalize the transitivity condition for that language and incorporate this condition into what we know about the category of subject. The present paper proposes such an analysis for Nez Perce.

The basic facts to be explained are shown in (1)-(2) below. As we see in these examples, the case system of Nez Perce shows a three-way patterning: intransitive subjects are unmarked for case, while both subjects and objects of transitive clauses are case-marked. ${ }^{2}$

(1) Intransitive: subject unmarked

a. sík'em hi-wlekix-tee'nix háamti'c. horse 3SUBJ-run-HAB.PL fast

Horses run fast.

b. hi-pa-k'oomay-na mamáy'ac. 3SUBJ-S.PL-be.sick-PERF children The children were sick.

c. Angel wéet'u hi-páy-ca-qa kii méeywi A NEG 3SUBJ-arrive-IMPERF-REC.PAST this morning Páyniwas-pa.

Payniwas-LOC

Angel didn't go to the Payniwas (café) this morning.

(2) Transitive: subject marked, object marked

a. 'ip-ním pée-qn'i-se qequii-ne. 3SG-ERG 3/3-dig-IMPERF edible.root-OBJ

He digs qequít roots. (Crook, 1999, 238)

b. pit'íin-im páa-yâx-na picpíc-ne. girl-ERG 3/3-find-PERF cat-OBJ

The girl found the cat.

\footnotetext{
${ }^{1}$ Nez Perce is a Sahaptian language spoken in Idaho, Washington and Oregon. Examples are from primary fieldwork unless otherwise noted.

2 Abbreviations in Nez Perce glosses are ERG ergative case, OBJ objective case, GEN genitive case, BEN benefactive case, LOC locative case, INST instrumental case, $3 / 3$ third person subject and third person object portmanteau verbal agreement, 30BJ 3rd person object agreement, 3SUBJ 3rd person subject agreement, O.PL plural object agreement, S.PL plural subject agreement, DIST distributive, IMPERF imperfective aspect (used for progressives and presently holding states), IMPERF.PL portmanteau marker for imperfective aspect and plural subject, PERF perfective aspect, HAB habitual aspect (used for habituals and generics), APPL1 goal applicative, APPL2 benefactive/malefactive/possessor applicative, CIS cislocative, FUT future, REC.PAST recent past tense, REM.PAST remote past tense, PART participle, NMLZR nominalizer.
} 
c. sik'ém-nim kúnk'u pée-wewluq-se timaaníi-ne. horse-ERG always 3/3-want-IMPERF apple-OBJ

The horse always wants an apple.

The subject case seen in (2) is a canonical ergative case in that it appears only on the subjects of transitive clauses, regardless of theta-role. ${ }^{3}$ Unlike in a canonical ergative system, however, it appears not with an absolutive- (or zero-) marked object, but only with an object bearing an overt objective case marker. ${ }^{4}$

The second basic set of facts to account for concerns a sort of differential casemarking. In addition to its unusual pattern of canonical case-marking, Nez Perce allows a type of clause in which both subject and object case-markers can go missing. Thus by contrast to the examples in (2) we have the examples in (3):

a. 'ipí hi-qn'íi-se qequiit. 3SG 3SUBJ-dig-IMPERF edible.root

He digs qequít roots. (Crook, 1999, 238)

b. pit'íin hi-yáâิ-na pícpic. girl 3SUBJ-find-PERF cat The girl found her cat.

c. ke 'itúu hi-wéwluq-se kúnk'u 'iceyéeye. something 3SUBJ-want-IMPERF always coyote

Coyote is always wanting something. (Aoki and Walker, 1989, 417)

Based on the morphology of this difference, I refer to clauses like (3) as CASELESS CLAUSES.

Caseless clauses and the three-way case-marking system of Nez Perce allow us to disentangle several different aspects of the category of transitive subject. We see first of all that ergative case is possible in the absence of absolutive case. This means we cannot capture the transitive subject simply as that core argument that remains for case-marking after absolutive is assigned (cf. Yip et al. 1987). And we see in cases like (3) that the precise formulation of the transitivity condition on ergative case is non-trivial in Nez Perce: certain clauses with two referential arguments, for instance (3b), prohibit the ergative (and objective) case.

The major empirical argument to be made here is that ergative case in Nez Perce is dependent on the syntax of the object, and not on lexical transitivity (i.e. the presence of a theme DP) or theta-role assignment. ${ }^{5}$ The form of the transitivity condition relevant to Nez Perce concerns object agreement: if the object can agree, both object and subject bear case. If the object is barred from agreement for whatever reason, case-marking for both subject and object is ruled out. Whatever the abstract syntactic properties of the subject may be, the realization of case-marking on subjects has

\footnotetext{
3 On the variety of theta-roles available for the transitive subject in Nez Perce, see section 4.1.

4 Thus, in terms of the common terminology, Nez Perce has an ergative case, but is not an "ergative language". See e.g. Hockett $(1958,235)$, "[in a language of] the ergative type: a case which we shall call the nominative appears for the subject of an intransitive verb and for the object of a transitive verb, while a second case, the ergative, appears for the subject of a transitive verb."

5 This is to say, the analysis here treats ergative as substantially dependent. Previous case dependency theories include Yip et al. (1987), Marantz (1991), Bittner and Hale (1996), McFadden (2004).
} 
to consider the syntax of another argument. It is this that constitutes the transitivity condition on ergative case.

In view of this transitivity condition, what can we say about the nature of ergative case? That ergative case comes about at the intersection of object agreement and subjecthood raises the intriguing prospect that ergative may be no more than the simple sum of these factors. The special case of the transitive subject need not be accorded the status of a grammatical primitive whose distribution is determined by factors involving subjecthood and transitivity; rather, it can be dissolved into subjecthood and transitivity. In this paper, I develop a new approach to ergative case whereby the ergative case marker is a morphological spell-out of the syntactic agreement system.

The plot is as follows. In section 2, I lay out the paradigms of case and caselessness in Nez Perce, along with their attendant agreement patterns. I then turn to the question of transitivity, arguing that the transitivity condition on ergative case in Nez Perce involves object agreement. In order to show that it is object agreement and not some other aspect of the syntax of objects that conditions case-marking, we must explore in some depth the syntax of caseless clauses. I show that caselessness is not a unified syntactic phenomenon (pace Rude 1985, Woolford 1997, Carnie and Cash Cash 2006). Two distinct syntactic configurations result in caselessness in Nez Perce, one a predicative object construction and one a binding configuration where agreement is blocked by an anaphor agreement effect. The two constructions are distinguished syntactically and semantically, but share the caselessness morphology. The fact that case-marking is blocked in these two separate instances, even in spite of their rather different syntactic and semantic properties, shows that the transitivity condition on ergative case does not directly reflect object interpretation; i.e. we cannot capture all instances of caselessness as "pseudo-incorporation" of the object (cf. Carnie and Cash Cash 2006). Rather, looking at the commonalities between the two types of caseless clauses, it is only the failure of object agreement that correlates systematically with the absence of ergative case.

To integrate this formalization of the transitivity criterion into a theory of subjecthood, I argue that the transitive subject should be defined as that argument which participates in subject agreement and with which object agreement features are shared (section 4). I then provide a locally calculable, post-syntactic account of case marking in Nez Perce using the tools of Distributed Morphology (Halle and Marantz, 1993), section 5. These tools allow us to adopt a reductionist approach to ergative: the ergative marker is inserted post-syntactically at a nominal node that bears the features of both subject and object. Nez Perce does not require any grammatical feature [ergative], syntactic or morphological. The paper concludes with an extension of the present analysis to Sahaptin, where ergative case on the subject depends on the person specification of the object. 


\section{Case and caselessness: the paradigm}

Nez Perce joins a genetically diverse set of languages with a three-way morphological distinction in core argument case-marking, all of them, unfortunately, understudied. ${ }^{6}$ Sentences (4) show the three forms: no case on intransitive subjects, e.g. picpic 'cat' in (4a); ergative $\mathrm{nm}$ or its allomorphs on transitive subjects, e.g. kinm picpícnim in (4b); and objective ne or its allomorphs on transitive objects, e.g. cu'yémne 'fish' in (4b). For neutrality, I provide no gloss for the absence of morphological case on intransitive subjects.

$$
\begin{aligned}
& \text { a. hi-pním-se pícpic. } \\
& \text { 3SUBJ-sleep-IMPERF cat } \\
& \text { The cat is sleeping. }
\end{aligned}
$$

b. ki-nm picpíc-nim pee-p-ú' cu'yéem-ne. this-ERG cat-ERG 3/3-eat-FUT fish-OBJ

This cat will eat the fish.

A key feature of the Nez Perce case system is that the two cases found in transitive clauses are not independent of one another: in most cases, the presence of ERG case requires the presence of OBJ case, and vice versa. ${ }^{7}$ Caveats of two types are relevant to this generalization. First, some nouns never inflect for one case or the other. This includes a few nominals such as 'iwéepne 'wife': here the single form 'iwéepne serves for both intransitive subject and transitive object (i.e., *'iwéepnene). In addition, as in many other languages, less than a full case paradigm is found for first and second person pronouns. ${ }^{8}$ In Nez Perce these pronouns fall into two classes: those which inflect for OBJ but not for ERG, e.g. ' iin $1 \mathrm{SG}$ and 'iim $2 \mathrm{SG}$, and those which do not decline at all, e.g. 'ee $2 \mathrm{SG}$ and kíye 1PL.INCL. These classes are exemplified in (5) and (6) respectively.

\footnotetext{
${ }^{6}$ Besides Nez Perce and closely related Sahaptin (for which see section 6), languages where nominals show three-way distinctions include Australian languages Pitta-Pitta (Blake, 1987), Wangkumara (Breen 1976, Blake 1987), Antekerrepenhe/Aranda (Strehlow 1944, Bittner and Hale 1996), Luritja (Holmer, 1963), Duungidjawu/Waga-Waga (Wurm, 1976), Thangu/Yuulngu (Wurm, 1976), and Yidin ${ }^{y}$ (Dixon, 1994, 87); Peruvian language Cashinawa (Dixon, 1994, 86); languages of Nepal such as Nepali (Bandhu, 1973) and Kham (Watters, 1973); Indian languages Nocte (Das Gupta, 1971), Marathi (Pandharipande, 1997), and Hindi; and Malaysian language Semelai (Kruspe, 2004). A larger class of languages could be considered to show a tripartite system if we include languages where both ergative/absolutive and nominative/accusative patterns are attested, but with different sets of nominals; e.g. in Australian languages such as Margany (Breen, 1981), pronouns show a nominative/accusative pattern whereas other nominals show an ergative/absolutive pattern. Discussion of languages with three-way case patterns and previous theoretical proposals can be found in Bittner and Hale (1996), Woolford (1997) and Legate (2008). My own view is that three-way languages form a diverse class, as ergative systems do more generally. The classification of languages as ergative/absolutive versus three-way is a typology of surface forms and not necessarily a guide to analysis.

7 This generalization supposes both subject and object are realized overtly. In Nez Perce texts and free discourse, this is rarely the case; however, argument drop has no effect on agreement or case-marking of other arguments. For this reason, I abstract away from null arguments here.

8 Yet this is not a universal of ergative languages or of three-way languages; e.g. Australian languages Pitta-Pitta and Wangkumara are fully three-way with no exception for pronouns.
} 
6

\begin{tabular}{ll|lll} 
person & number & intrans subject & trans subject & objective \\
\hline 1st person & singular & 'iin & 'iin & 'íine \\
& plural inclusive & kíye & kíye & kíye \\
& plural exclusive & nuun & nuun & núune \\
\hline 2nd person & singular & 'iim & 'iim & 'imené \\
& & 'ee & 'ee & 'ee \\
& plural & 'imé & 'imé & 'imúune \\
& & 'eetx & 'eetx & 'eetx \\
\hline 3rd person & singular & 'ipí & 'ipním & 'ipné \\
& plural & 'imé & 'iméem & 'imúune
\end{tabular}

Table 1 The pronominal system

(5) a. 'iin lilóoy-ca.

1SG be.happy-IMPERF

I'm happy.

b. 'iin wéet'u 'itúu-ne 'aa-p-sá-qa.

1 SG NEG INDEF-OBJ 3OBJ-eat-IMPERF-REC.PAST

I didn't eat anything.

c. ciq'áamqal-m hi-ke'níp-e 'íin-e.

dog-ERG 3SUBJ-bite-PERF 1SG-OBJ

The dog bit me.

(6) a. kíye ku-síix múut'e-tx.

1 PL.INCL go-IMPERF.PL downstream-to

We are going downstream.

b. kíye 'a-kat'a'w-cix laláx-na 'etke

1PL.INCL 3OBJ-drink.up-IMPERF.PL coffee-OBJ because

hi-yaw'icwi-yo'.

3SUBJ-become.cold-FUT

We should finish (are finishing) the coffee because it will get cold.

c. 'inpe'weet-úm kíye hi-naas-payn-óo-yo'!

police-ERG 1PL.INCL 3SUBJ-O.PL-arrive-APPL1-FUT

The cops might come upon us!

The pronominal system is summarized in table 1. In addition to the person split in the expression of ergative case between 1st/2nd and 3rd person pronouns, we observe as well that all three indeclensible pronouns include a 2nd person feature (assuming that a 1 st person inclusive bears both first and second person features). The nature of this person split remains at present a topic for further research. ${ }^{9}$

Further interference in the mutual dependence between subject and object cases in the transitive clause can come about when the subject contains a genitive modifier.

\footnotetext{
9 The major challenge for the study of pronouns, and indeed the reason this topic cannot be satisfactorily treated here, is the relation between the ergative and the genitive. These cases are, to my knowledge, in every way morphophonologically identical in Nez Perce, except for their distribution with 1st/2nd person pronouns: those pronouns that inflect at all do inflect for genitive, but never for ergative. For present purposes we might assume that this pattern shows that ergative and genitive forms are listed as separate vocabulary items, though an explanation for that state of affairs is still lacking.
} 
According to Rude (1985), the presence of genitive case within a nominal phrase blocks the expression of ergative and objective case on the head of the phrase. ${ }^{10}$ Thus, in contrast to (7), where the subject bears ERG case, genitive haamanm 'man's' blocks case on ciq'áamqal 'dog' in (8).

(7) ciq'áamqal-m pá-'naxpay-ka pipís-ne.

dog-ERG 3/3-bring-PERF bone-OB J

The dog brought the bone. (Rude, 1985, 198)

(8) háama-nm ciq'áamqal pá-’naxpay-ka pipís-ne.

man-GEN dog 3/3-bring-PERF bone-OBJ

The man's dog brought the bone. (Rude, 1985, 198)

Agreement and object case-marking are unaffected in such examples.

As verbal inflection varies along with case-marking in caseless clauses, a summary is in order here. Person marker morphemes occupy the leftmost prefix position in the verb word; overt person prefixation is for third persons only. ${ }^{11}$ Number agreement follows person agreement, with subject number agreement to the left of object number agreement. With plural subjects, verbs either prefix pe- or suffix -ix (depending on aspect); with plural objects, verbs prefix nées-. Clauses with 3rd person subject and 3rd person singular object prefix pée (where subject agreement is prefixal, there is the additional criterion that the subject be singular); clauses with 3rd person objects and a 1 st/2nd person subject prefix ' $e$; otherwise, clauses with 3 rd person subjects prefix $h i$. Table 2 summarizes.

The case and agreement systems converge on the notions of subject and direct object. If any nominal is marked ERG, it will be that nominal controlling subject agreement; if any nominal is marked OBJ, it will be that nominal controlling object agreement. Object agreement and object case go hand in hand. If the object marks case, it must agree; if it agrees, it must mark case (unless it is not overtly realized at all). Subject agreement, on the other hand, picks out the subject nominal even in

\footnotetext{
${ }^{10}$ Rude reports this pattern as absolute; for my consultants, the blocking is optional, with a preference for case to be marked.

(i) 'íin-im ciq'áamqal(-nim) pée-p-teetu nukúu-ne. $1 \mathrm{SG}$-GEN dog-ERG 3/3-eat-HAB meat-OBJ My dog eats meat.

This difference may reflect dialect variation or language change.

11 This rather sharp person split in verbal inflectional morphology is counterbalanced by person inflection on certain typically clause-initial particles: these particles agree with 1st/2nd person arguments, but never with 3rd persons. Crook $(1999,214)$ suggests that this pattern results from reanalysis of secondposition clitics (such as are still found in Sahaptin) originally ordered 2 nd person $i 1$ st person $i 3$ rd person; the 2 nd and 1st person inflections are presently found as suffixes on typically clause-initial items, whereas the 3 rd person inflections are prefixes on verbs. Interestingly the same plural morpheme, pe, is found in both systems. The following example shows the agreeing particle weet, marker of yes/no questions.
}

(i) wéete-pe-m-ex náas-apaa-p-o'-qa cepéepyux̂tin'?

Y.N-PL-2-1 O.PL-CAUSE-eat-FUT-REC.PAST pie

Can I make you (pl) eat some pie? (Crook, 1999, 216) 
A. The person marking system.

\begin{tabular}{c|ccc} 
& subject & object \\
\hline 1st & - & & - \\
2nd & - & & - \\
\hline 3rd & hi- & pé & 'e
\end{tabular}

B. The number marking system.

\begin{tabular}{l|cc} 
& subject & object \\
\hline $\begin{array}{l}\text { singular } \\
\text { plural }\end{array}$ & - & - \\
pe- or -iix & nees-
\end{tabular}

C. Combined paradigm (prefixal subject number agreement)

\begin{tabular}{|c|c|c|c|c|c|c|}
\hline & & no obj & $\begin{array}{l}\mathrm{O} \\
1 / 2 \mathrm{sg}\end{array}$ & $\begin{array}{l}\mathrm{B} \\
1 / 2 \mathrm{pl}\end{array}$ & $\begin{array}{l}\mathrm{J} \\
3 \mathrm{sg}\end{array}$ & $3 \mathrm{pl}$ \\
\hline $\bar{S}$ & $1 / 2 \mathrm{sg}$ & - & - & nees & e & 'enees \\
\hline $\mathrm{U}$ & $1 / 2 \mathrm{pl}$ & pe & pe & penees & 'epe & 'epenees \\
\hline B & $3 \mathrm{sg}$ & hi & hi & hinees & pee & hinees \\
\hline $\mathrm{J}$ & $3 \mathrm{pl}$ & hipe & hipe & hipenees & hipe & hipenees \\
\hline
\end{tabular}

Table 2 Verbal inflection for person and number

\begin{tabular}{l|cccc} 
& subject agr & subject case & object agr & object case \\
\hline canonical & $\mathrm{Y}$ & $\mathrm{Y}$ & $\mathrm{Y}$ & $\mathrm{Y}$ \\
caseless & $\mathrm{Y}$ & $\mathrm{n}$ & $\mathrm{n}$ & $\mathrm{n}$ \\
intransitive & $\mathrm{Y}$ & $\mathrm{n}$ & &
\end{tabular}

Table 3 Summary of case and agreement patterns

the absence of subject case, i.e. in intransitives. It retains its role as identifier of the subject regardless of the case of the subject nominal, whether ERG in a transitive or unmarked in an intransitive.

Overall, the case and agreement paradigms show similarity between caseless clauses and intransitive clauses. While all clauses show subject agreement, only canonical transitive clauses show object agreement and case-marking. This is summarized in Table 3. A note on terminology is in order here. Below, I argue that the 'caseless' row in Figure 3 has only a morphological status, not a syntactic one. Syntactically, caseless clauses are not a natural class. There is not cause to reach such a conclusion for cased clauses (e.g. (2a), (4b), (7)), however. I maintain that cased clauses represent the transitive morphology and syntax of Nez Perce. Therefore, since we can identify the cased morphology with syntactic transitivity, I refer to such clauses as TRANSITIVES. ${ }^{12}$

A final factor to make note of in this introductory section is notable primarily for its irrelevance to the problem of case-marking; this factor is word order. Word order varies in transitive examples and in caseless examples. It serves a discourse function, as discussed by Rude (1992). In the discussion below I abstract away from this variation, assuming a strictly configurational grammar for Nez Perce, and (as an

\footnotetext{
12 Terminology differs across previous accounts; most notably, the transitive clause type is labelled 'ergative' by Rude (1985 et seq.). Previous treatments of the clause type alternation include Aoki (1970, 1994); as a voice alternation, Rude (1985), Crook (1999); as a case alternation, Woolford (1997), Carnie and Cash Cash (2006). Of these, only Crook (1999) suggests that caseless clauses may be syntactically diverse, noting that "intransitive morphology is found with transitive verbs in two kinds of situations. One is akin to possessor raising ... The other is a kind of antipassive" (p. 237).
} 
arbitrary choice) depict a VO order for the Nez Perce VP. We will see some reason to assume that Nez Perce is indeed configurational (in particular, a subject-object asymmetry in binding) as the discussion proceeds. ${ }^{13}$

\section{The transitivity condition}

We turn now to the question of what it means for ergative case to target the transitive subject, beginning with the question of transitivity. In contrast to the more traditional view, which takes transitivity to be a feature of verbs themselves, recent theoretical work has largely taken a decompositional approach, positing that transitivity is created or at least represented by functional structure separate from the verb itself (i.a. Bowers 1993, 2002, Kratzer 1996, 2003, Legate 2006). Perhaps the best-known version of this approach is that which takes external arguments to be introduced not by the verb itself but by a functional head or 'light verb' $v$ or Voice (Kratzer, 1996). I will call this family of theories the $v$-model. This model has well-explored semantic and syntactic arguments in its favor (see e.g. Marantz 1984, Kratzer 1996, 2003, Pylkkänen 2002), though I will not review them here.

(9) $v$-model:

External arguments are not introduced by verbs (V), but by a separate piece of functional structure $(v)$.

An important consequence of the $v$-model's decompositional approach is that it requires us to to find a new conception of transitivity that does not rely on any semantic or lexical distinction between transitive and intransitive Vs. This is because the task of introducing external arguments, the second argument taken to yield the transitivity of many verbs, has been decomposed out into the $v$ head. Thus a transitive verbal projection like that in John found Allen is represented as a $v \mathrm{P}$ which, while transitive overall, contains no head that introduces two arguments. ${ }^{14}$

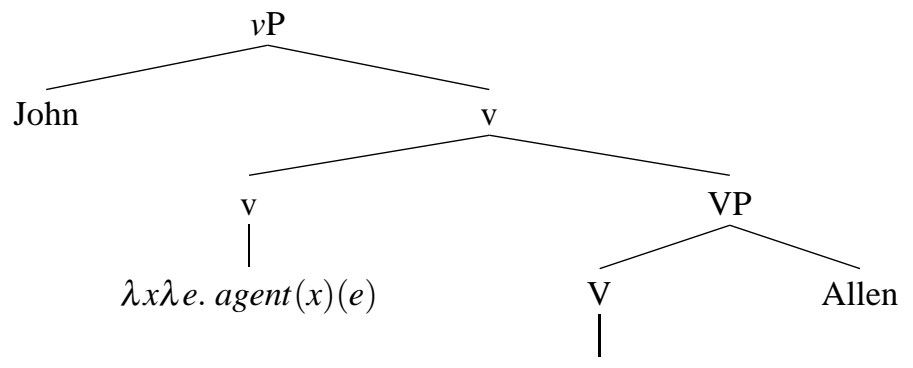

find: $\lambda y \lambda$ e. finding $(y)(e)$

\footnotetext{
13 I assume that word order freedom in Nez Perce is created by rather free movement into the C-domain. In support of this proposal, relative clause material can sometimes appear to the left of the relative clause complementizer, suggesting it dominates at least some of the C-domain.

14 In this paper I adopt a moderate version of the $v$-model which takes theme arguments to be introduced by verbs. It is possible to adopt a more radical version of this model and decompose out the object as well, as in Borer (2005); see Kratzer (2003) for arguments against this proposal. In either case a new definition of transitivity is required.
} 
Integrating the $v$-model with a structural approach to the unergative/unaccusative distinction, we find that functors just like those in (10) are found in intransitives as well: unergatives contain $v$ introducing their external argument, and unaccusatives contain a verb root like that in (10) introducing their internal argument. ${ }^{15}$

(11) John jumped [unergative]

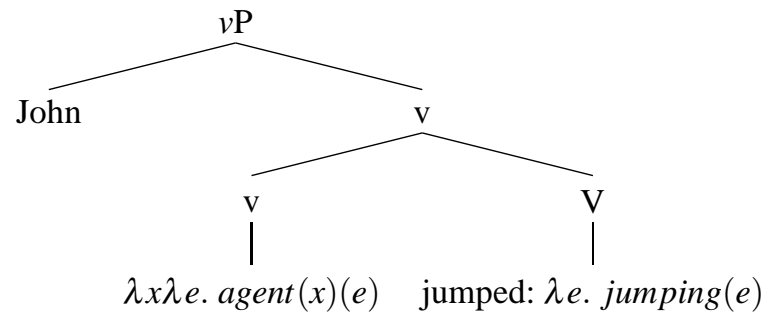

(12) John grew [unaccusative]

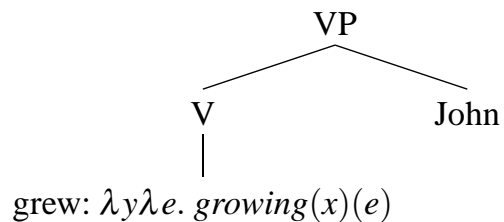

Thus we cannot say that transitivity results either from the presence of $v$ or from the presence of a $\mathrm{V}$ that takes an argument. If the $v$-model is to be maintained, some additional factor must be introduced in order for a language to systematically distinguish a class of transitives from both unergative and unaccusative intransitives, as is the case in Nez Perce and other ergative languages. In this section, I argue that the factor that distinguishes between transitive and intransitive clauses in Nez Perce is the presence of object agreement.

The data most crucial to the study of transitivity in Nez Perce come from caseless clauses (see section 2), clauses which share their case pattern with intransitives but have two arguments instead of one. Two minimal pairs of transitive and caseless clauses are repeated below.

a. 'ip-ním pée-qn'i-se qeqiii-ne. 3SG-ERG 3/3-dig-IMPERF edible.root-OBJ He digs qequiit roots. (Crook, 1999, 238)

b. 'ipí hi-qn'îi-se qequiit. 3SG 3SUBJ-dig-IMPERF edible.root

He digs qequíit roots. (Crook, 1999, 238)

a. pit'ín-im páa-yâx-na picpíc-ne. girl-ERG 3/3-find-PERF cat-OBJ The girl found the cat.

\footnotetext{
15 Unaccusatives may also contain a $v \mathrm{P}$ projection, though with a $v$ head that does not introduce an argument. See Deal (to appear) for some evidence that this might be the case.
} 

b. pit'ín hi-yáẫ-na pícpic.
girl 3SUBJ-find-PERF cat
The girl found her cat.

Caseless clauses show that the presence of two arguments is not sufficient to render a clause transitive in the sense relevant to case-marking in Nez Perce. Clauses like (14b) show that even assuring the referentiality of these two arguments will not do the trick.

This section shows that caseless clauses, and hence the factors underlying the transitivity effect in Nez Perce, are heterogeneous in origin. Two separate sets of conditions bleed case-marking: a predicative object construction and a binding configuration that blocks agreement. While the constructions both concern the syntax of the object and are morphologically indistinguishable, their syntax and semantics diverge in several notable ways. I argue that the major commonality between caseless clauses due to predicative objects, e.g. (13b), and those due to binding, e.g. (14b), is the failure of object agreement. It is object agreement, therefore, in terms of which the transitivity condition on Nez Perce ergative case must be stated.

\subsection{The heterogeneity of caselessness: the evidence}

A distinction between two types or functions of caseless clauses is recognized in the descriptive literature dating to Rude (1985). Rude notes that caselessness has two syntactic/discourse functions: to encode what he calls a "non-topical" object, and to encode that the subject is the object's possessor. These correspond to cases (13b) and (14b); further examples of each type are given below.

(15) "Non-topical object"

páax̂loo ha'áyat hi-'x̂ni-síx qémes.

five.HUM women 3SUBJ-dig-IMPERF.PL camas

Five women are digging camas. (Phinney, 1934, 185)

(16) Subject $=$ object possessor

$$
\begin{aligned}
& \text { hi-wéwluq-se c'olákstimt xaâxaac. } \\
& \text { 3SUBJ-want-IMPERF hand.drum grizzly } \\
& \text { Grizzly wants his hand-drum. (Phinney, 1934, 83) }
\end{aligned}
$$

Rude makes an important first distinction between the two cases. In the first case, where the object is merely "non-topical", caselessness is grammatically optional; the transitive construction may also be used with a comparable meaning (see e.g. minimal pair (13)). In the second case, however, caselessness is obligatory. If a transitive construction is used, the meaning of possession is lost. This is seen in (14) and in the following pair from Aoki $(1994,381)$.

a. 'iin láwlimq-sa pískis. 1SG fix-IMPERF door

I am fixing my door. 
b. 'iin 'a-láwlimq-sa piskís-ne.

1SG 3OBJ-fix-IMPERF door-OBJ

I am fixing a door.

I refer to clauses like (17a) where subject binds object possessor as EXTENDED REFLEXIVES, following Aissen (1999, 473).

Below, I show that optionally caseless clauses like (13b) and (15) are predicative object constructions or ANTIPASSIVES (as they are translated; the strings are themselves ambiguous), syntactically and semantically different from transitive clauses, whereas extended reflexive caseless clauses like (14b) and (17a) share the syntax of transitive clauses despite their caseless morphology. ${ }^{16}$ The two constructions diverge on a number of tests. First, on the definiteness and referentiality of the object: antipassive objects are weak indefinites, whereas extended reflexive objects are typically definite. In terms of scope, antipassive objects cannot scope over the distributive quantifier $w i$-, whereas extended reflexive objects must. Finally, the two constructions have different distributions: antipassive is restricted to theme arguments, whereas extended reflexives encompass applicative arguments and goals.

\subsubsection{Evidence from definiteness}

Extended reflexive clauses typically have definite objects. This is true under two senses of "definite": these objects typically pick out referents that are unique (within some salient domain), and often also pick out referents that are discourse-old. ${ }^{17}$ The following examples involve referents that are unique.

(18) hekí-ce 'íin-im iníit.

See-IMPERF $1 \mathrm{SG}$-GEN house

I see my house.

(19) píke héetewi-se

mother love-IMPERF

I love my mother

In the following case, we see that an extended reflexive is felicitous where the object is discourse-old. In extended reflexive clause (20e), the object (Coldweather's father) has been mentioned in each of the four previous clauses.

(20) [From Warmweather and Coldweather, Aoki and Walker $(1989,62)]$ One day Coldweather's father ordered her, "Go and visit your uncles [the Warmweathers] and see how they are." Then she started from there. Coldweather dashed into the Warmweather teepee. She sat down and squatted there. "You are the

\footnotetext{
16 The use of the term 'antipassive' here follows Rude 1985 et seq. The Nez Perce antipassive differs from a classical antipassive construction in not showing oblique case on the object (which I take to be a low-level effect) and in not showing an antipassive morpheme in the verb. See Deal (2007) for an argument that the semantic composition of property-type object constructions in Nez Perce is mediated by a covert antipassive morpheme.

17 On the importance of distinguishing two kinds of definiteness, see Schwarz (2008).
} 
image of hunger," said the old man [Warmweather], and he threw a piece of liver at her. She caught it and gobbled it as she ran back.

a. pist hi-wéeleylek-uu-kike, father 3SUBJ-run-APPL1-PERF.TRANS

She ran into her father,

b. 'isíimet hi-wáawsiqatk-sa qiiwn

behold 3SUBJ-sit.with.legs.spread-IMPERF old.man

behold, the old man is sitting there

c. kaa 'ip-ním-ke páa-tamy-a'n-ya k'íma-ki sit'ex̂s-ki and 3SG-ERG-too 3/3-throw-APPL2-PERF half-INST liver-INST

And she too threw a half liver at him

d. kaa pá-tamtay-na,

and 3/3-tell-PERF

and she told him,

e. pist hi-hí-ne ku'ús hi-wyáakaa'aw-cix.

father 3SUBJ-say-PERF thus 3SUBJ-live-IMPERF.PL

to her father she said, "Thus they are living."

Such discourses confirm the possibility of definite semantics for extended reflexive objects.

The objects of antipassives, by contrast to extended reflexives, can only be indefinite. Antipassives are not felicitous where the object is discourse-old. This can be seen in the following example, where the context gives us a discourse-old referent, a particular house in Lewiston. If we use the antipassive construction, 'iniit 'house' cannot refer to this house that has been under discussion. It must introduce a novel referrent into the discourse. Note that this does not obtain in the transitive sentence, (21a).

(21) Context: One house in Lewiston is red, and yesterday, John found that house.

a. Cáan-nim páa-'yax̂-na 'iníi-ne. John-ERG 3/3-find-PERF house-OB J

John found the house.

b. Caan hi-’yáâx-na 'iníit.

John 3SUBJ-find-PERF house

John found a house.

Comment: "It's not referring to the red house or anything, it's just he just found a house that he's been looking for"

Antipassives are also infelicitous where the object is a referential term, for instance a proper name.

(22) Context: we're organizing a ballgame and picking players for our teams.

a. nuun 'e-wewluq-siix Harold-ne pox̂pok'líit-ki.

1PL 3OBJ-want-IMPERF.PL H-OBJ ballgame-INST

We want Harold for the ballgame. [transitive] 
b. \# nuun wewluq-siix Harold pô̂pok'líit-ki.
1PL want-IMPERF.PL H ballgame-INST

Intended: We want Harold for the ballgame. [antipassive]

Where proper names can be used non-referentially, antipassives are licit. Certain intensional contexts allow proper names to be interpreted indefinitely. (23) shows such an example. The names Meli and Cosef here do not refer to any particular individuals; rather, what is expressed is a desire for unspecified individuals meeting the description 'a Mary' and 'a Joseph'.

(23) kísmis-pe sapátk'ayn wewluq-siix Meli kaa Cosef.

christmas-LOC show want-IMPERF.PL Mary and Joseph

For the Christmas show we want a Mary and a Joseph.

On the basis of definiteness effects and scopal behavior, Deal (2007) argued that antipassive objects in Nez Perce are predicative or "non-specific", which we can formalize semantically as being of a property-type, $\langle e, t\rangle$ (see van Geenhoven 1998, Farkas and de Swart 2003, Chung and Ladusaw 2004, Deal 2008b). ${ }^{18}$ Crosslinguistically, property-type objects are a subclass of indefinites in that they cannot refer to entities already established in a discourse context (Mohanan 1995, van Geenhoven 1998, Farkas and de Swart 2003; cf. the analysis of certain definites as property-type by Zimmermann 1992).

What we see in these data overall is that caseless clauses bifurcate in the range of interpretations available to the object: antipassive objects must be indefinite, whereas extended reflexive objects can be definite. In this way the extended reflexive patterns with the transitive and not with the antipassive, although it is caseless. Thus, we cannot hold either case-marking or its absence responsible for referentiality/definiteness in Nez Perce; we also cannot implicate object interpretation as the decisive factor behind the transitivity condition, since caseless clauses like (18) have fully definite, referential objects.

\subsubsection{Evidence from VP quantification}

Cross-linguistically, predicative objects are restricted to narrowest scope. I suggested above that antipassive objects are predicative, but extended reflexive objects typically are referential. We predict then that antipassive objects should be scopally inert whereas extended reflexive objects should be able to take scope over other operators. The verbal distributive prefix wi- provides scopal evidence confirming this prediction, distinguishing extended reflexives from antipassives. In line with the definiteness facts, extended reflexive objects behave like transitive objects, whereas antipassive objects are a class apart.

While Nez Perce has several quantifiers that appear in its nominal phrases, e.g. óykalo/a 'everyone/thing', la' ám 'all', these do not require distributive quantification. The distributive quantifier is a verbal prefix wi-, which appears between inflectional

\footnotetext{
${ }^{18}$ Semantic types used in this paper are $e$, the type of entities (objects), $t$, the type of propositions, and $s$, the type of events.
} 
prefixes and derivational ones. The structural position of this quantifier invites comparison to VP-quantifiers in familiar languages, e.g. each in (24).

(24) The kids will each feed the horse.

The presence of a VP quantifier in Nez Perce has no effect on case or agreement. The argument with which the quantifier associates (or: over which it distributes) is in general determined on an 'absolutive' basis. In a transitive clause, wi- associates with the case-marked object, rather than the subject (Rude 1985, 42, Crook 1999, 135):

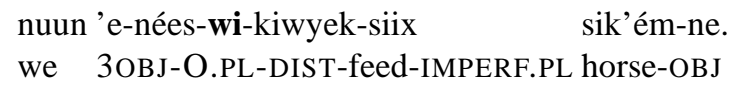

In a transitive clause, the use of wi- requires a semantically plural object. ${ }^{19}$ If the object is singular, the quantifier cannot be used, (27b).

\section{a. Distribution over plural object}

Taqc ti-téeqis-nim hi-nées-wi-wewkuni-se today PL-elder-ERG 3SUBJ-O.PL-DIST-meet-IMPERF hitemeneweetúu-ne. student-OBJ Today the elders are meeting with each student.

NOT: Today the elders are each meeting with (the) students.

b. Singular object: can't use quantifier

Taqc ti-téeqis-nim pee-(*wi-)wewkuni-síix Harold-ne. today PL-elder-ERG 3/3-(*DIST-)meet-IMPERF.PL Harold-OBJ Today the elders are (*each) meeting with (*each) Harold.

We can treat such examples as cases where the object nominal has escaped the scope of the distributive operator. Instead of forming part of the predicate that is distributed over individuals (e.g. feeding in (25)), the transitive object escapes and becomes the element of which the distributed property is predicated. Structurally speaking, the nominal associates with the quantifier by moving to a position immediately above the quantifier. Thus, in (25), a property of being fed is predicated distributively of a plurality of horses. (28a) schematizes syntactically, and (28b) schematizes the semantic interpretation of such a structure. ${ }^{20}$

\footnotetext{
19 The object does not have to be morphologically marked for plural, but it must denote a plurality. Most Nez Perce nouns do not inflect for number. In (27a) the form hitemeneweetúune 'student-OBJ' can pick out either a singular student or a plurality of students; the latter possibility enables the use of DIST.

20 The position of the lambda term in (28b) is related to the way movement is interpreted here: movement of the nominal creates a predicate, and DIST operates over this predicate (roughly: requiring it to be a predicate that applies to a plurality only if it applies to each atomic part of the plurality). The resulting property is predicated of the moved nominal.
} 
a.

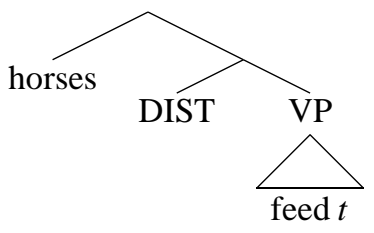

b.

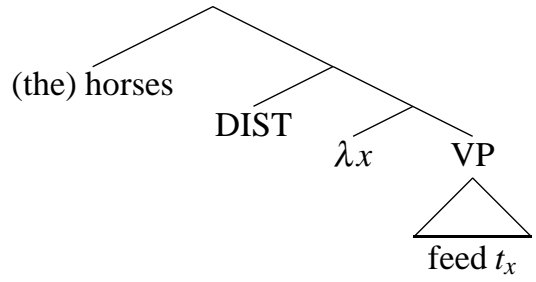

Here the DIST head merges lower than the $v$ head which introduces the agent argument, meaning that the object does not have to move across the subject in order to arrive at Spec,DIST. It seems reasonable to assume that the movement of the object, in (25) sik'emne 'horses', to Spec,DIST is related to those factors independently known to move referential/presuppositional objects out of VP (Diesing, 1992). This helps us understand the effect in (27b), where a singular object in a transitive clause bars the use of wi-: if the object can move to Spec,DIST, then DIST can only associate with the object (i.e., it cannot associate with the subject). As the singular referential object can move out of VP, DIST must associate with it; but this is ruled out on semantic grounds.

In an intransitive clause, wi- distributes over the subject, regardless of agency:
a. hahácwaal hi-pe-wí-wece-ye
sik'ém-pe. boys 3SUBJ-S.PL-DIST-mount-PERF horse-LOC The boys each got on a horse.
b. 'éete hi-pe-wí-ti'nx-ne 'ilx̂ní-we titóoqan. surely 3SUBJ-S.PL-DIST-die-PERF many-HUMAN person Surely many people have each died. (Phinney, 1934, 21)

Unaccusatives, such as (29b), can be explained just as in (28a), with the underlying object subsequently becoming the subject. In unergatives, however, there is no nominal within VP which can move to Spec,DIST. In a v-model, agent arguments are arguments of $v$, not of the verb itself; therefore, the predicate that DIST will need to render distributive in an unergative is in fact the agency predicate itself. (For example, predicated of 'boys' in (29a) is the distributed property of being the agent of a mounting event.) Thus, DIST must be merged above $v$ in unergatives. ${ }^{21}$

With this background, we turn again to contrasts between the antipassive and extended reflexive. In an antipassive clause, wi- distributes over the subject, paralleling the intransitive case (Rude, 1985, 160):

\section{(30) a. Context: an egg hunt}

\footnotetext{
21 It is not clear why DIST cannot more generally be merged above $v$, giving rise to distribution over the agent even in the presence of an object (e.g. in (25), (26)). More research is needed on this point.
} 
mamáyac hi-pa-wí-'yax̂-na táam'am.

children 3SUBJ-S.PL-DIST-find-PERF egg

The children each found eggs (but perhaps not all eggs were found).

NOT: The children found each egg (but perhaps not all children were egg-finders).

b. 'óykal-oo hi-wíi-'nep-tin'ix weptées-nim tu'úynu.

all-HUMAN 3SUBJ-DIST-hold-IMPERF.PL eagle-GEN tail.feather

They each are holding eagle tail feathers. (Aoki, 1979, 84)

NOT: They are holding each feather.

This finding accords well with the facts above about the interpretation of antipassive objects. We saw that antipassive objects cannot be definite and proposed that they are predicative, property-type. Property-type indefinites (by contrast to referential terms) are candidates for existential closure. In keeping with Diesing's mapping hypothesis, this suggests that the antipassive object remains within VP, failing to move out to Spec,DIST. Since nothing can move to its specifier to serve as its argument, DIST cannot be merged below $v$, and distribution can only occur over the agent argument, as in the unergative. ${ }^{22}$

In an extended reflexive clause, by contrast, the object is typically definite and not subject to existential closure. Accordingly, the object leaves VP and wi-produces a distributed property which is predicated of it, paralleling the transitive case:

a. haháacwal hi-pe-wí-kiwyek-e sík'em.
boys 3SUBJ-S.PL-DIST-feed-PERF horse

The boys $i$ fed each of their ${ }_{i}$ horses.

b. hi-wí-hex-ni-me láwtiwaa-ma.

3SUBJ-DIST-See-PERF-CIS friend-PL

$\mathrm{He}_{i}$ saw each of his $i_{i}$ friends. (Phinney, 1934, 273)

On this test, as before, extended reflexive objects behave like transitive objects and unlike antipassive objects; here, only the former scope over the distributive marker. In both transitive and extended reflexive, the object leaves VP and can move to Spec,DIST. This is in spite of the fact that extended reflexive clauses are caseless, arguing, interestingly, that the factor that drives movement out of VP cannot be the need to check a particular case.

\footnotetext{
22 This approach attempts to explain both why the antipassive object does not associate with the distributive quantifier and why the antipassive subject does do so. The former fact could alternatively be explained as a consequence of the obligatory indefiniteness of antipassive objects, given that indefinites generally do not associate with VP quantifiers (see Dowty and Brodie 1984):

(i) The students each left.

(ii) * Students each left.

(iii) * Some students each left.
}

Something else must be said to account for why antipassive subjects are able to associate with the distributive quantifier where the object cannot, by contrast to transitive subjects with singular objects (see (27b)). 


\subsubsection{Evidence from thematic restrictions}

As final evidence for a syntactic distinction between extended reflexives and antipassives, the two phenomena do not have the same distribution. The extended reflexive binding configuration can bring about caselessness on applicative objects, goal objects and the object of heki 'see'; antipassivization is not possible in any of these cases.

The applicative suffix - $(y) u ́ u$ - adds an goal argument to a transitive or intransitive clause; the goal argument is marked with object case marking. Case marking is not available for a theme or other object in this case, as shown in (32).

(32) qo’c tax̂c kii(*-ne) 'ew-nehki-yúu-yu' qúiwn-e.

yet soon this(*-OBJ) 3OBJ-take-APPL1-FUT old.man-OBJ

I will soon take this to the old man. (Phinney, 1934, 146)

The extended reflexive configuration produces caselessness on applicative objects (Rude, 1986, 145), while antipassive cannot. Thus, (33) can only have an extended reflexive interpretation, and not an antipassive one.

(33) sík'em hi-k-yúu-ye.

horse 3SUBJ-go-APPL1-PERF

He went over to his own horse.

NOT: He went over to horses/a horse.

Similar facts are found with double object verbs. Here, as in the case of the overt applicative, only the goal argument, not the theme, may receive case-marking and agree with the verb. (34a) exemplifies. It is not possible to antipassivize this sentence, as shown in (34b).

$$
\begin{aligned}
& \text { a. 'ipéê̂ hi-nées-kiwyek-se qetqéet-ne 'áayat-om. } \\
& \text { bread 3SUBJ-PL.OBJ-feed-IMPERF duck-OBJ woman-ERG } \\
& \text { The woman is feeding bread to the ducks. } \\
& \text { b. * 'ipéê̂ hi-kíwyek-se qétqet 'áayat. } \\
& \text { bread 3SUBJ-feed-IMPERF duck woman } \\
& \text { intended: The woman is feeding ducks bread. }
\end{aligned}
$$

Despite the ungrammaticality of antipassive (34b), caselessness is indeed possible in double object sentences if it is due to an extended reflexive. (35) exemplifies. ${ }^{23}$

$$
\begin{aligned}
& \text { 'áayat hi-kíwyek-se pícpic cúu'yem. } \\
& \text { woman 3SUBJ-feed-IMPERF cat fish } \\
& \text { The woman is feeding fish to her own cat. }
\end{aligned}
$$

\footnotetext{
${ }^{23}$ My consultant noted in this case that the order pícpic cú'yem is required; the goal must precede the theme. This is notable as word order is not generally revealing as to thematic role or syntactic position in Nez Perce.
} 
Again in this case, the non-theme argument is obligatorily case-marked except in an extended reflexive. Antipassivization is not available to produce caselessness on the non-theme object.

A third restriction of this type is found with the verb heki 'see'. No matter how seemingly non-referential the object of this verb is, consultants do not allow antipassive; (36) shows that the transitive structure is mandated even with a negative indefinite object ('nothing') or a property object ('red'). ${ }^{24}$

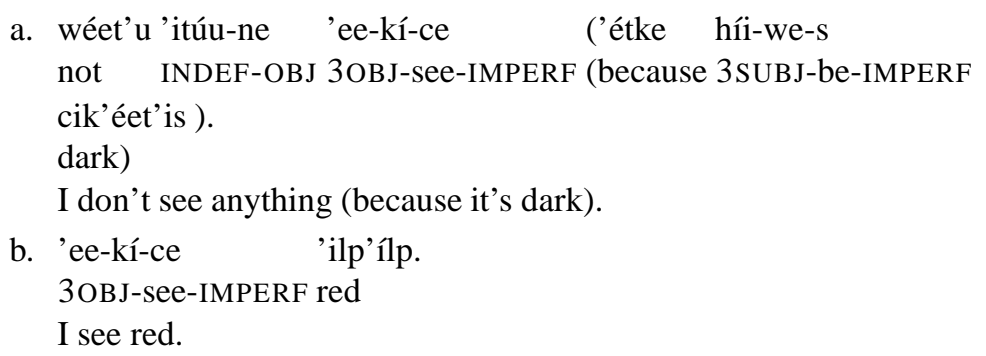

The generalization that emerges from the facts overall is that antipassivization is restricted to theme arguments. This generalization re-emerges cross-linguistically: Baker (1988, section 7.2.3.2) notes that regardless of which nominal is chosen for case-marking or agreement in a particular language, only themes can incorporate and antipassivize. ${ }^{25}$ In light of this finding, we may want to analyze hekí 'see' as taking a goal argument, perhaps rendering it more similar to 'look at' than to 'see' per se. The pattern with arguments to this verb repeats once more the generalization from applicative objects and goals in double object sentences: antipassive cannot apply to the non-theme object, but extended reflexivity may render it caseless. An example repeated from above shows caselessness with heki in an extended reflexive.

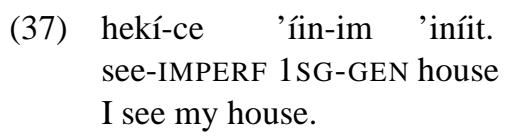

Like caseless clauses with applicatives and double objects, caseless clauses with the verb heki are not ambiguous. They may only have an extended reflexive interpretation.

We have now seen convergent evidence from four sources for a distinction between antipassive caseless clauses and extended reflexive caseless clauses. First, antipassives alternate with transitives in a way that preserves the basic propositional meaning; extended reflexives cannot alternate with transitives without losing their binding pattern. Secondly, antipassive objects can only be indefinite, whereas extended reflexive objects are typically definite. Third, antipassive objects cannot scope

\footnotetext{
24 Note that although 'ilp'ilp 'red' does not take ОвJ case in (36b), object agreement on the verb unambiguously identifies the transitive structure. Case concord between noun and adjective is generally optional in Nez Perce.

25 This effect may be approximated with English incorporating agentive nominals such as money sender, but *home sender (except on the reading 'someone who sends homes').
} 
over the distributive morpheme wi-, whereas transitive objects and extended reflexive objects must do so. Finally, extended reflexives have a wider distribution than antipassives do: only extended reflexivity can bring about caselessness on applicative objects, goals, and the object of heki 'see'.

We turn now to the structure of antipassives and extended reflexives, seeking to know what, despite their syntactic and semantic differences, causes them to share the caseless morphology, and so be classified as 'intransitive' in terms of case-marking. We will see that the uniting factor is the failure of agreement with the object. Object agreement fails in the antipassive due to the structure of the object; the antipassive object is too small to agree. In the extended reflexive, the problem is not the structure of the object itself but an anaphor agreement effect (Rizzi 1990, Woolford 1999).

\subsection{The structure of antipassive objects}

Following much work on the cross-linguistic semantics of scopally restricted, nonreferential objects (e.g. on Nez Perce, Deal 2007; on Eskimo languages, van Geenhoven 1998, Wharram 2003 (cf. Bittner 1987, 1994); on Hindi, Mohanan 1995, Dayal 2003; on Hungarian, Farkas and de Swart 2003; on Maori and Chamorro, Chung and Ladusaw 2004), I assume that antipassive objects in Nez Perce are of a property type, $<e, t>$. This is also the type of the common noun (see e.g. Heim and Kratzer 1998). ${ }^{26}$ By contrast to antipassive objects and bare common nouns, referential DP objects are of type $e$. This suggests that the semantic function of (non-quantificational) determiners is to produce names (i.e. expressions of type $e$ ) out of predicates (i.e. expressions of type $\langle e, t>$ ). Such determiners are functors of type $<e t, e>$.

Since the semantic type of antipassive objects is the same as that of common nouns without determiners, the simplest hypothesis is that antipassive objects are NPs, projections of nouns which remain of type $\langle e, t\rangle$ because no determiner has come along to make them be of type $e .{ }^{27}$ While Nez Perce does not have overt determiners with which to test this prediction, other languages such as Hungarian are known to prohibit determiners in their non-referential objects (Farkas and de Swart, 2003). The non-referential nominal is visibly structurally smaller than the referential DP, lacking at least the D layer. What else remains of the rich functional structure of nominals (Szabolcsi 1987, Ritter 1991), e.g. the projection(s) associated with $\phi$ features (Déchaine and Wiltschko 2002)?

The world's languages vary in whether or not non-referential objects are able to agree with verbs. In Hindi, such objects agree (Dayal 2003); in Inuktitut, they do not (Wharram, 2003). I propose that this difference results from whether languages allow a $\phi$-head to occur on the edge of a nominal in the absence of a D head. We know that $\phi$-features and D are tightly linked in many languages. Germanic and Romance languages encode both $\phi$ and definiteness in single morphemes, for instance, and we find similar correlations in typologically and genetically far-flung languages. In Northern

\footnotetext{
26 Relational nouns most likely require a higher type $(<e, e t\rangle)$, though once supplied with an argument (forming NP) they are also $\langle e, t\rangle$.

27 This analysis requires that individual languages allow both NP and DP arguments. See Pereltsvaig (2006) for an demonstration of this fact in Russian and other languages.
} 
Pomo, a Hokan language of Northern California, nominal phrases headed by common nouns can overtly mark $\phi$-features on their right edge only in case an overt D-element is present (O'Connor 1992: 172-179). ${ }^{28}$ This marking, which O'Connor analyzes as a pronoun, is absolutely inseparable from the rest of the nominal and cannot be stressed, distinguishing itself in these regards from resumptive pronouns.

a. masan maata (nam)

D optional

white woman DEF

(The) white women

b. masan maata *(nam) phow

$\phi$ requires $D$

white woman DEF 3PL

Those white women (O’Connor, 1992, 174)

Just as in better-known Indo-European cases, the presence of a D head in the Northern Pomo DP is tightly linked to the expression of the nominal's $\phi$-features. Unlike in the Germanic and Romance cases, Northern Pomo permits the presence of D without $\phi$; it does not, however, allow $\phi$ without $\mathrm{D}$. The presence of the $\phi$-head depends on the presence of the D head.

What role does a $\phi$ head play in the grammar of nominals? We might entertain the hypothesis that this head appears on the edge of the nominal in order to allow features from the noun to be accessible outside the noun phrase. We might posit, therefore, a locality barrier in the nominal projection, which $\phi \mathrm{P}$ is outside but the $\mathrm{N}$ head is inside. Agreement probes from outside the nominal projection cannot reach all the way down into the nominal structure to reach $\mathrm{N}$ itself; accordingly, nominals project a $\phi \mathrm{P}$ on their edge. Now, while we cannot directly see a $\phi$ projection on the edge of the DP in Nez Perce, the absence of agreement in antipassives can be predicted straightforwardly if Nez Perce is exactly like Northern Pomo in allowing $\phi$ to be projected just in case $\mathrm{D}$ is. The antipassive object lacks $\mathrm{D}$, and therefore $\phi$ cannot be projected. This is to say that $\phi$-probes in the clausal structure (e.g. $\mathrm{T}^{29}$ and the head responsible for object agreement) will be unable to agree with the antipassive object, as no $\phi$-features are accessible on its edge. ${ }^{30} 31$

\subsection{The structure of extended reflexives}

In section 3.1 we saw that in terms of scope and referentiality, extended reflexive objects behave like transitive objects. In this section, I present an account of extended

\footnotetext{
28 Northern Pomo is a head-final language.

29 In this paper I refer to the head which controls subject agreement as T. Note that Nez Perce is not a tenseless language; tense may be seen in (1c), for instance. Tense markers combine with the imperfective and habitual aspects; present tense is not overtly marked, thus when these markers occur without an overt tense marker the interpretation is present. The perfective does not combine with tense and always has a past time interpretation. The perfect also does not combine with tense and has a past time interpretation with eventive verbs in the absence of higher structure.

30 Note that in such cases the locality barrier in the nominal projection must remain, suggesting that $\phi \mathrm{P}$ and DP are not responsible for this barrier. Thanks to Omer Preminger for raising this issue.

31 On the broader question of how antipassive clauses are structured in Nez Perce such that the verb takes a property-type object, see Deal (2007).
} 
reflexives that accounts for their obligatory caselessness while assuming a transitivelike syntax and semantics. The essence of the account is that while extended reflexive clauses are underlyingly transitive, their objects are blocked from agreeing by an anaphor agreement effect (Rizzi 1990, Woolford 1999). In Nez Perce object nominals it is generally the case that the possessor is accessible to outside probes in a way that the overall object nominal is not: the object possessor is externalized and participates in verbal agreement instead of the overall object nominal. In the extended reflexive construction, the possessor is a bound variable. Building on work by Kratzer (to appear), I analyze bound variables as syntactically and semantically featureless. In an extended reflexive clause, the object possessor is the most accessible nominal for object agreement, closer than (the features of) the overall nominal within which it resides; agreement targets it, and comes away featureless. This failure of object agreement is what is responsible for the similarity with the antipassive construction, and for the overall caselessness of the extended reflexive.

The argument to be given has several parts. I first argue that extended reflexives involve binding. I then show that extended reflexives come about in exactly those contexts where object possessor externalization is to be expected. Accordingly, I propose that both extended reflexive and possessor externalization are grammatical results of the same fact: in Nez Perce objects, outside probes targeting the object nominal interact with the possessor, not the overall nominal. I then sketch my analysis in terms of an anaphor agreement effect. General discussion of the reflexive morphology of Nez Perce and the reasons it is not found in extended reflexive constructions can be found in the appendix.

\subsubsection{Binding}

The first fact to be demonstrated is that the caselessness effect we see in Nez Perce extended reflexives is indeed a matter of binding. As expected on a binding approach, a possessor bound by a quantificational subject requires caselessness:

(39) 'óykala haháacwal píke hi-hetewi-tee'nix. all boys mother 3SUBJ-love-HAB.PL All boys love their mothers.

Configurational evidence backs up the case from variable binding. Caselessness is required when subject binds object possessor. It is not possible when subject possessor is coindexed with object. This subject-object binding asymmetry is accounted for straightforwardly if Nez Perce is underlyingly configurational, despite its surface freedom of word order. The subject c-commands the object possessor asymmetrically. The following pair, from adjacent clauses in a traditional story, illustrate this contrast. ${ }^{32} 33$

\footnotetext{
32 As is typical in Nez Perce, pronouns are not expressed overtly in these examples. Speakers often consider overt pronouns "emphatic", in keeping with cross-linguistic patterns.

33 The verb root $h i$ 'say, tell' in (40b) is phonologically obliterated owing to the presence of stressed prefix pée.
} 
(40) a. píst hi-hí-ne

father 3SUBJ-tell-PERF

She told her father (Phinney, 1934, 71)

[ $\operatorname{pro}_{i}\left[\right.$ told [ $\operatorname{pro}_{i}-$ GEN father ] ] ]

b. pée-ne pisít-pim

3/3-tell-PERF father-ERG

Her father told her (Phinney, 1934, 71)

[ [ $\operatorname{pro}_{i}$-GEN father ] [ told $\operatorname{pro}_{i}$ ] ]

In (40a), where the object possessor is bound by the subject, caselessness ensues. In (40b), by contrast, the possessor within the subject nominal is coindexed with the object pronoun, but does not c-command it and hence cannot bind it (in the sense of Chomsky 1981). Accordingly, the sentence is transitive.

\subsubsection{The connection to external possession}

Although extended reflexive caselessness comes about in a binding configuration, this configuration is not the most typical context for binding effects: after all, it is the object possessor that is being bound by the subject, not the object itself. This distinction is obscured in Nez Perce, however, in virtue of a requirement that object possessors be expressed as verbal arguments. In the resulting EXTERNAL POSSESSION construction, an applicative morpheme, ey', appears on the verb; the erstwhile possessor is expressed as direct object, showing case-marking and agreeing with the verb. ${ }^{34,35}$ Examples are in (41). (Italics in the English translation mark the nominal that behaves as direct object.) In (41b), for instance, verbal agreement registers a firstperson singular object by failing to show overt object agreement at all (see Figure 1); a third person object (as the overall object 'my cat' would be) would have required the $3 / 3$ prefix pée-.
a. ki-nm háacwal-m likíp pée-kiy-e'n-ye 'ip-né samî. this-ERG boy-ERG touch 3/3-do-APPL2-PERF 3SG-OBJ shirt This boy touched her shirt. (Aoki, 1979, 60)

\footnotetext{
${ }^{34}$ Keeping the focus here on caselessness, I will not have space to fully survey and analyze external possession constructions in Nez Perce. See Rude (1999) for discussion of external possession in Nez Perce and closely related Sahaptin.

35 Mandatory possessor externalization, in combination with the language's rather complex morphophonology, may in some circumstances give the false impression of caselessness. Example (i), analyzed by Carnie and Cash Cash (2006) as caseless, is such an instance.

(i) póo-pci'yawn-a'y-sa-na kúks-ne miyác.

3/3-kill-APPL2-IMPERF-REM.PAST Cook-OBJ child

They killed Cook's son. (Aoki, 1979)

Here vowel harmony combines with a glide reduction rule to obscure the pée- prefix on the verb. (Underlyingly, the verb 'kill' is wep-ci'yaw, 'with.hand-be.violent' (Aoki, 1994, 44). /ewe/ $i$ /uu/ is a regular sound change in Nez Perce, and /uu/ harmonizes to /oo/.) Kúksne míya'c is not a constitutent in this structure; kúks-ne is the object, showing object case marking, and miyá'c is the caseless theme argument.
} 
b. 'áayat-om hi-kiwyek-ey'-kse 'ín-e pícpic cúu'yem. woman-ERG 3SUBJ-feed-APPL2-IMPERF 1SG-OBJ cat fish The woman fed $m y$ cat fish.

c. 'ee-xn-éy'-se píke X-ne. 3OBJ-See-APPL2-IMPERF mother X-OBJ

I see $X$ 's mother. (Aoki, 1994, 109)

d. kaa wáaqo' weptées-ne simées and now eagle-OBJ bed pée-x-yuu-'ey-se-ne wex̂weqé-nm. 3/3-go-APPL1-APPL2-IMPERF-REM.PAST frog-ERG

And now the frogs went to the eagle's bed. (Phinney, 1934, 229)

As examples (41) show, object possessors are expressed externally regardless of whether the object DP is a theme (41a), a goal (41b), the object of hekí 'see' (41c), or an applicative object (41d). Recall that these are all environments in which extended reflexive caselessness obtains (section 3.1.3).

We have now seen that in each type of clause where extended reflexive caselessness is mandatory, object possessor externalization is also mandatory. This suggests that the same factors that force an object possessor to be expressed as a verbal argument also force an object possessor that is bound by the subject to bring caselessness crashing down on its clause. The tight distributional connection between the two phenomena extends in both directions. We have seen that in the types of configurations where the extended reflexive binding pattern brings about caselessness, object possessor externalization is mandatory. We will see now that where an object possessor cannot be externalized, caselessness does not ensue if the possessor is bound by the subject.

In a ditransitive construction, verbal agreement targets the theme, not the goal. The possessor of the goal can be externalized, (41b), but the possessor of the theme cannot be; thus (41b) cannot mean 'The woman fed my fish to a/the cat'. Where possessor externalization is not possible from the theme, caselessness does not ensue if the subject binds the possessor of the theme.

(42) 'în 'ew-'ní-ye 'ín-im ciq'áamqal háama-na. 1SG 3OBJ-give-PERF $1 \mathrm{SG}-\mathrm{GEN}$ dog man-OBJ I gave my dog to the man. (Aoki, 1994, p. 40)

(43) 'iwéep-nim wáaqo' pe-'én-ye laqáas-na c'oláakstimt. wife-ERG already 3/3-give-PERF mouse-OBJ hand.drum The wife already gave her hand-drum to the mouse. (Phinney, 1934, 82)

The identical distribution of extended reflexive caselessness and possessor externalization extends to cases where the possessor cannot be expressed externally for morphological reasons. Nez Perce has two types of possessive marking: an independent genitive phrase, as seen above in (42) and schematized in (44), and a form of synthetic possessor marking, as shown in (45). The synthetic marking is only available for first and second person possessors and only applies to a limited set of nouns, almost exclusively kinship terms. The two types of possessive marking do not occur in the same nominal. 
(44) Productive possessive marking:

personal pronoun genitive suffix independent nominal

'iin -im píst 'my father'

(45) Special kinship term marking:

possessor prefix dependent stem form

na- 'tóot 'my father'

Cases of possessor externalization involve independent nominal forms, and so we might view externalization as being fed by the analytic possessor forms. Possessor externalization never leaves a dependent stem form behind: by contrast to (46a), for instance, we never find forms like (46b).
a. hexn-éy'-se pist 'imu-né.
see-APPL2-IMPERF father ${ }_{\text {[ree stem] }} 2 \mathrm{SG}-\mathrm{OBJ}$
I see your father.
b. * hexn-éy'-se 'toot 'imu-né. see-APPL2-IMPERF father [dep sem] $^{2}$ SG-OBJ
intended: I see your father.

Again, extended reflexive caselessness tracks the possibility of external possession. When the object possessor is expressed synthetically, possessor externalization is not possible and extended reflexive caselessness does not come about.

a. qó'c wéye na-'tóot-ap 'e-séepn'i-yu'. yet soon 1 $1 \mathrm{sG}$-father-OBJ 3OBJ-ask-FUT

Yet soon I will ask my father. (Aoki, 1979, 50)

b. na-'yác-ap 'eeteex 'aw-'yáqi-n.

1SG-brother-OBJ surely 3OBJ-find-PERFECT

Surely I found my brother. (Aoki, 1979, 30)

In sum, we have seen that extended reflexive caselessness and external possession have the same distribution. We now turn to an analysis of why this connection should hold.

\subsubsection{Analysis}

In the external possession construction, the possessor is treated as a verbal argument; it is case-marked and agreed with. In addition, the verb bears a special suffix, ey' ${ }^{36}$ Independent of external possession, this morpheme behaves like an applicative. In (48), the most natural interpretation is benefactive: the mean one benefits from the people's work. In (49), the most natural interpretation is malefactive: when the geese spread out, Coyote will drop into the water and presumably drown.

\footnotetext{
36 This morpheme is subject to allomorphy depending on the following segment; thus it differs from (48) to (49) given the difference in aspect/mood morphology following.
} 
(48) [From Cut-Out-of-Belly Boy, Aoki and Walker 1989, 375.] Cut-Out-of-Belly Boy comes across people who have been enslaved and are pounding sunflower seeds. They explain:

'e-kiyé-e'y-s-ix cika'wíis-na.

3OBJ-do-APPL2-IMPERF-S.PL mean-OBJ

We are doing this for the mean one.

(49) [From Warmweather and Coldweather, Aoki and Walker 1989, 55.] The goose brothers are carrying Coyote (who has married their sister) on their wings as they cross the water. After Coyote insults them, the eldest goose says:

kawó' cik'íiw-ne k'ay'áx 'e-kiye-é'n-ix.

then brother.in.law-OBJ spread.out 3OBJ-do-APPL2-IMPER

Then spread out on the brother-in-law!

In keeping with the possibility for both benefactive and malefactive interpretations, I interpret the ey' applicative as introducing an argument which is affected by the event described by the verb. ${ }^{37}$

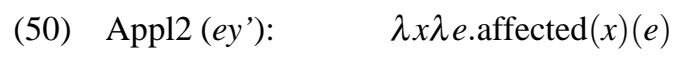

I analyze external possession constructions as a special case of the applicative construction. The possessor moves from within the object nominal to the specifier of the applicative. It is interpreted in two places: as a possessor, due to its interpretation in the nominal, and as an affected party, due to its interpretation as the applicative's argument.

(51) 'iceyéeye-ne sílu pée-'nehweec-ey'-six. coyote-OBJ eye 3/3-dance-APPL-IMPERF.PL

They are dancing with coyote's eyes. (Aoki and Walker, 1989, 146)

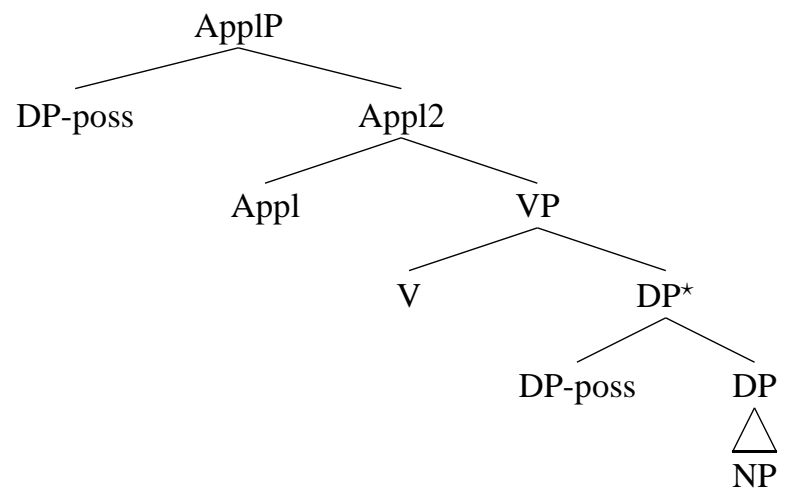

The external possession cases like (51) differ from the pure applicative cases like (48) in that they recycle an already-interpreted nominal as the applicative argument. ${ }^{38}$

\footnotetext{
37 This reflects a very common affectedness requirement in external possession cross-linguistically (Payne and Barshi 1999, O'Connor 2007).

38 This derivation requires that there be no extraction prohibition on possessors in Nez Perce, and indeed it appears that there is not. Possessors may appear separated from nouns, though they only do so infrequently in corpora.
} 
I analyze the similarity between extended reflexive constructions and external possession constructions as coming about due to the status of the possessor inside the object nominal in the two cases. ${ }^{39}$ If the possessor is to be externalized in a case like (51), it must be accessible to outside probes that drive movement. Suppose that in a structure like (52) the probe is Appl, as seems reasonable. When Appl probes into its sister, it ignores $\mathrm{DP}^{\star}$ (the overall object nominal) in favor of the possessor DP inside of it. This suggests that within the object nominal, the possessor's features are closer to an outside probe than the overall object nominal's features are. ${ }^{40}$

This gives us the structure we need to explain why caselessness obtains in an extended reflexive. The object possessor's features are always closer to an outside probe than the overall object's features are. The grammar does not generally allow probes to target the overall nominal and agree with it if a possessor is present; the possessor intervenes. Now suppose that the possessor is a bound variable. What does this mean for its agreement behavior? In order to agree, we demand only that at the point in the derivation where the agreement takes place, the bound variable has features that it may share with the agreement probe. Yet recent work on the morphosemantics of binding has revealed that bound variables often present instances of morphologysemantics mismatch; in many cases, the features that we infer from the morphology of bound items are not themselves semantically interpreted on the bound items. This can be seen cases of "fake indexicals" as in (53).

(53) Only you eat what you cook.

One reading of this example treats the second instance of you, ostensibly an indexical, as a bound variable: you are the only $x$ such that $x$ eats what $x$ cooks. This bound variable ranges not only over second persons (those being addressed by (53)), but over relevant individuals more generally. How is this bound variable semantics to be reconciled with the visible person features of you?

(i) kaa wáaqo' 'ipsúus-x kike't hi-'npi-me 'icweew'lcix-nim. and now hand-to blood 3SUBJ-take-PERF.CI monster-GEN And now he took the monster's blood on his hands. (Phinney, 1934, 25)

(ii) ke 'im-éem tim'úune pist 'e-pe-wc'ee-ye REL 3PL-GEN bow father 3POSS.S-S.PL-become-PERF those whose father became a bow (Aoki and Walker, 1989, 137)

39 Note that extended reflexive is not derived from external possession, but rather the two are made possible by the same fact about the structure of possessed object nominals.

40 Since DP ${ }^{\star}$ dominates DP-poss, on standard assumptions about c-command, neither c-commands the other. If locality is calculated in terms of closest c-command, the two potential goals should count as equidistant from higher probes. There is a choice of conclusions to draw from this. Perhaps the most modest, accepting equidistance between DP-poss and $\mathrm{DP}^{\star}$, is to conclude that such equidistance must be resolvable in favor of agreement with DP-poss in at least some configurations. A second possible move is to reject the equidistance between DP-poss and $\mathrm{DP}^{\star}$ by adopting a revised version of c-command, for instance Kayne's (1994). A third possibility is to eschew equidistance by rejecting the premise that agreement targets DP. If it is $\phi \mathrm{P}$ that is targeted by agreement, as proposed above, then it may be possible to treat the $\phi \mathrm{P}$ within DP-poss as closer to outside probes than the $\phi \mathrm{P}$ within $\mathrm{DP}^{\star}$. Of course, this option depends on the possibility of $\phi \mathrm{P}$ within DP-poss being "closer to the top" than $\phi \mathrm{P}$ within $\mathrm{DP}^{\star}$, a proposal that requires a non-uniform functional structure for nominals (pace Cinque 1999). I leave the choice among these options to future research. 
On the basis of (53) and a range of related examples, Kratzer (1998, to appear) has argued that bound variables can be represented in the syntax, and interpreted by the semantics, without any $\phi$-features at all. What apparent features they have can be assigned to them in post-interpretation morphology/morphosyntax. If this is the case, we might understand what comes about when the object agreement probe comes across the bound variable possessor as follows: the probe finds a nominal (perhaps the index feature which comprises the bound variable, in Kratzer's terms), but it does not find any $\phi$-features to share. Object agreement, in the sense of $\phi$-feature transfer, fails in extended reflexives. The closest nominal to the object agreement probe has no $\phi$-bundle to share with the probe. ${ }^{41}$

This explanation for the failure of object agreement in Nez Perce extended reflexives renders them an example of the ANAPHOR AGREEMENT EFFECT (Rizzi, 1990). As pointed out in Rizzi's original discussion of the topic, effects attributable only to an inability of anaphors to agree, and not to other facets of the binding theory, are seen in the grammar of Italian, exemplified below. The Italian verb piacere 'like/please' takes a (non-agreeing) dative subject and a nominative object, which agrees with the verb. ${ }^{42}$

(54) A loro piaccio io. to 3PL.DAT please.1SG I.NOM

They like me.

If the nominative object is an anaphor, however, agreement is blocked, (55). Such examples only become grammatical if verbal agreement switches to a default $3 \mathrm{SG}$ form, (56).

$$
\begin{aligned}
& \text { * Mi piaccio me stesso. } \\
& \text { me please-1SG myself } \\
& \text { intended: I like myself. }
\end{aligned}
$$

$$
\begin{aligned}
& \text { ? Mi piace me stesso. } \\
& \text { me please-3SG myself } \\
& \text { I like myself. }
\end{aligned}
$$

What we see in these examples is an inability of bound variable nominals to share $\phi$ features with agreement probes. The Italian pattern is quite similar to what we have seen for Nez Perce above. If a nominative object (in Italian) or an object possessor (in Nez Perce) is not a bound variable, it participates in agreement. However, like the Italian nominative object, if the Nez Perce object possessor is a bound variable, it cannot participate in agreement. In this case, the probe responsible for object agreement probes the possessor nominal, but this nominal does not share $\phi$-features with the probe. Accordingly, there are no $\phi$-features to realize as object agreement.

Work by Woolford (1999) has shown that anaphor agreement effects are found in a variety of unrelated languages. Woolford notes that one of two things happens

\footnotetext{
41 This treatment presupposes that Agree operates before the post-syntactic operations that give speakable $\phi$-features to bound variables. I assume here that Agree operates in "narrow syntax" and is realized in the morphological component, as is commonly but not universally (e.g. Bobaljik 2005) assumed.

42 Thanks to Ilaria Frana for help with the Italian data.
} 
cross-linguistically when agreement attempts to target an anaphor: the agreement goes simply missing, or it assumes a special "anaphoric" form. I interpret this latter option as coming about when a language has a way of expressing agreement that does not depend on having any $\phi$-features to express. The agreement head can only mark that it has agreed, but cannot give any particulars of the item that it has agreed with. ${ }^{43}$ 44

In overview, I propose that the structure of extended reflexive constructions is parallel to the structure of transitives. The difference between the two comes about due to the inability of the object possessor to agree. It is generally the case in Nez Perce that within object nominals, possessors are accessible to outside probes in a way that possessed nominals are not. This allows possessors to be externalized and to participate in object agreement.

When the possessor is a bound variable, however, any probe that seeks to agree with it will find no $\phi$-features to share. Therefore, no object agreement is realized in the extended reflexive. This anaphor agreement effect has ramifications for the case system. Although a case-marking contrast is not visible in the Italian data, presumably because nominative is equivalent to the absence of morphological case, casemarking in Nez Perce tracks the agreement facts entirely. When the object can agree, it is marked for case. When it cannot (e.g. as the theme argument in a ditransitive), it remains caseless. The inability of objects to agree is what unites the extended reflexive construction and the antipassive in Nez Perce, providing for their unified caselessness in spite of their syntactic and semantic differences.

\subsection{Summary}

Our exploration of caseless clauses converges on object agreement as the factor responsible for transitivity in the sense relevant to Nez Perce ergative case. We have seen that where object agreement is blocked due to the absence of $\phi \mathrm{P}$ (as in antipassives) or an anaphor agreement effect (as in extended reflexives), both subject and object case-marking disappear. For object case-marking, this finding is not surprising; case and agreement go together for the object (as they do for subjects in many languages). But the sensitivity of the subject case to object agreement remains the special quirk of the ergative system, the core of its transitivity effect.

In the sections that follow we move toward a formalization of the transitivity effect, first considering what criterion of subjecthood it is best combined with, and ultimately proposing a morphological analysis of the case system according to which the ergative case is a spell-out result of object agreement.

\footnotetext{
${ }^{43}$ In Deal (2008a), the special, underspecified form of agreement found with reflexives in Warlpiri is proposed to derive from the presence of only a [D] feature on bound variable objects.

${ }^{44}$ Note that for Nez Perce it is not possible to examine the agreement properties of anaphors that are not embedded in other nominals (e.g. anaphor objects bound by the subject) given that the language requires detransitivization whenever possible in reflexives. Data and argumentation can be found in the appendix.
} 


\section{The subjecthood criterion}

The task is now to put together what we have learned about the transitivity condition with a condition on subjecthood. To do so, we must choose between several conceptions of subjecthood which are in many cases equivalent: the agent; the argument belonging to the highest argument-structural specifier position within an extended verbal projection; or the argument entering into an agreement relation with higher functional structure. I first show that ergative is not restricted to agents in Nez Perce. I then show that we cannot adopt a purely argument-structural notion of subjecthood on the grounds of evidence from causatives.

\subsection{Ergative is not the case of agents}

A characterization of ergative as the case of transitive subjects stands in empirical opposition to a view of ergative as the case of (transitive) agents. In particular, we can distinguish between a view according to which ergative is a structural case for transitive subjects (i.e. a case assigned given a particular syntactic configuration), and one according to which it is an inherent case for agent arguments (i.e. a case assigned given a particular theta-role), as proposed by Woolford (1997). ${ }^{45}$

In the ideal situation for an inherent case view, ergative is licensed or assigned just in case the argument to which it is assigned receives the agent theta-role. However, this is not the situation in Nez Perce. Ergative case appears on transitive subjects that lack the characteristic properties of agents, e.g. animacy and volition, or are standardly assumed to hold $\theta$-roles other than agent. In Nez Perce, the ergative case is realized on transitive subjects even if these are subjects of psych-verbs:

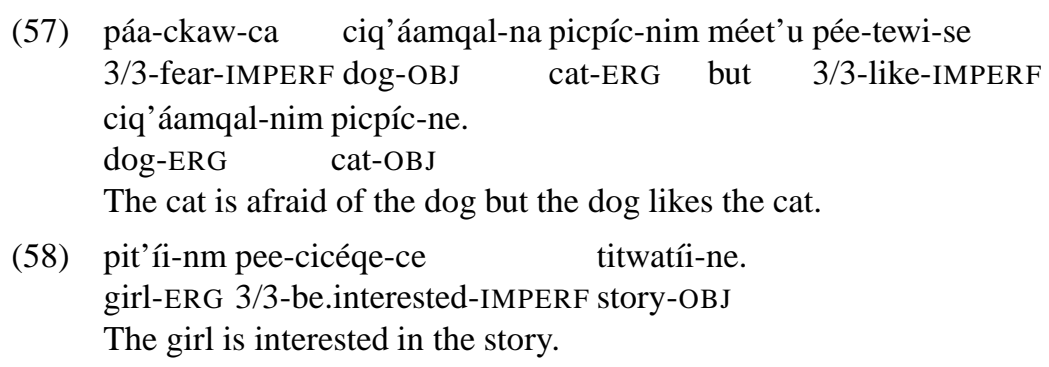

Non-agentive causer subjects are treated the same way:

(60) púu-ye-sitk-en'-ye wéyux hopóop-nim.

3/3-quickly-entangle-APPL2-PERF leg moss-ERG

The moss entangled her legs. (Phinney, 1934, 16)

\footnotetext{
45 The link between ergativity and agentivity has been a topic in the typological literature for quite some time; see Comrie (1978), and for a recent recap, Bruening (2007).
} 
(61) Context: discussion of a car wreck atop Lewiston Hill. In dense fog, a small car crashed into a large truck hauling cars to a dealership.

himéeqiis-nim 'aatamóoc-nim póo-yawq-na kuckúc-ne 'aatamóoc-na. big-ERG car-ERG 3/3-wreck-PERF little-OBJ car-OBJ

The big car wrecked the little car.

Comment: "caused him to get in a wreck"

So too are natural forces and even what seem to be undergoers:

(62) hahatyan-óo-sa 'icewe'íis-nim háatya-nm.

be.windy-APPL1-IMPERF cold-ERG wind-ERG

Cold wind is blowing towards me. (Aoki, 1994, 100)

(63) tax̂c 'ee hi-tqewéeleylek-e'n-yu' mac'áyo kúus-nim.

soon 2SG 3SUBJ-flow.into-APPL2-FUT ear water-ERG

Water will flow into your ears. (Aoki and Walker, 1989, 112)

(64) piswé-m iníi-ne pee-tqilikéece-ye.

rock-ERG house-OBJ 3/3-fall.on-PERF

A rock fell on the house.

In all these examples, ergative case tracks transitive subjects (where subjecthood is determined by subject agreement) but not necessarily agents. A strict version of the agency proposal undergenerates, in that it predicts that non-agentive subjects should lack the ergative case. This issue is anticipated in Woolford 1997, where it is noted that "although the correlation between ergative Case and the agent theta role is not perfect, it is as close as the correlation between dative and goals/experiencers is" (p. 182). What I want to claim here is that this imperfect correlation between agency and ergative in Nez Perce arises because of the well-known imperfect correlation between agency and subjecthood. ${ }^{46}$ The predictive power of our theory is not enhanced by a view of ergative as a case for agents that is nevertheless sometimes assigned to nonagents.

\subsection{Ergative is not thanks to $v$ alone}

We turn now to a second potential conception of subject: the subject is that nominal that occupies the highest argument-structural position in a verbal projection. Such a conception is suggested by a family of recent proposals that treat ergative case as an inherent case whose assignment is controlled purely by $v$ (e.g. Woolford 2006, Aldridge 2004, Legate 2002, 2006, 2008, Anand and Nevins 2006). On such a treatment, we might propose that the transitivity condition in Nez Perce reduces to a choice between two $v$ heads. One requires object agreement and assigns ergative ("transitive $v$ "); the other is incompatible with agreement and with ergative

\footnotetext{
46 As Comrie (1978) put it: "It should be noted initially that there is bound to be a high correlation between ergative noun phrases and agentive noun phrases simply because As [transitive subjects] are typically high on the scale of agentivity."
} 
("intransitive $v$ "). ${ }^{47} 48$ I will refer to this intermediate hypothesis as the 'Agreeing $v$ ' hypothesis.

(65) Agreeing $v$ hypothesis:

The difference between transitive and intransitive clauses lies in the syntax of the $v$ head only. Transitive $v$ but not intransitive $v$ participates in object agreement and assigns/licenses ergative case to its specifier.

Before we test this hypothesis, we will need to make specific the means by which object agreement is encoded in grammar. My treatment of agreement is purely syntactic. ${ }^{49}$ It appears that object agreement is in principle available to any but the highest argument in an argument-structural projection; agreeing objects include not only themes but also goals in ditransitives and applicative objects. However, only one agreeing object is allowed per external argument. We can propose then that object agreement features are bundled with the highest argument-introducing head in a verbal projection:

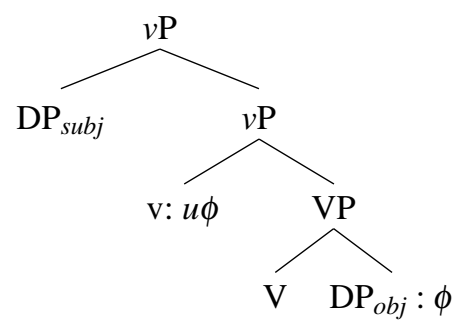

Here $v$ is the highest argument-introducing head. The agreement feature on this head consists of an unvalued $\phi$-bundle that receives its value through agreement with the closest c-commanded nominal. In (66) I have shown this as a theme argument; were another argument introduced above the theme, such as a goal or an applicative argument, this argument would be closer to the $u \phi$ probe and in consequence control object agreement.

Here is how we might come to the Agreeing $v$ hypothesis: if object agreement features come bundled with the highest-argument structural head, and the argument introduced by that head ends up being the subject, could we not reduce the transitivity condition on ergative case to this lucky coincidence in $v \mathrm{P}$ structure? Ergative subjects would be just those subjects originating in a $v \mathrm{P}$ with fully valued $\phi$-features.

Yet evidence from causatives speaks against the Agreeing $v$ hypothesis. The causative construction with transitive verbs is the only case I know of in Nez Perce where we

\footnotetext{
47 On some models of this variety, transitive and intransitive $v$ are also taken to differ in whether they combine with a transitive verb (e.g. Legate 2006). However, as we have seen, the $v$-model does not allow us any real notion of transitivity/intransitivity in verbs themselves.

48 Note that on this approach, agreement and case features are both directly encoded in the syntax, with no obvious connection between them.

49 This is necessitated by my treatment of bound variables as syntactically featureless. Agreement must apply before the morphological processes that give speakable (but not interpretable) features to bound variables.
} 
see two independent case-marked objects within a single clause: the embedded subject (the 'causee') bears objective case, and so can the object of the verb (the 'underlying object'):

(67) síisel kaa mársi-na 'e-née-sepe-twik-ce céeki-ne.

$\mathrm{C}$ and M-OBJ 3OBJ-O.PL-CAUSE-accompany-IMPERF J-OBJ

I make Cecil and Marcie accompany Jackie. (Crook, 1999, p 180)

The plural object agreement we see here reflects agreement with the causee, 'Cecil and Marcie'. The presence of the agreement morpheme indicates a syntactic agreement relation between the causee and the highest $v$, that introducing the (ergative) causer argument.

What about the lower $v$, introducing the causee? While there is no agreement morpheme spelling out agreement between this head and the verbal object in (67), there are several indications that the verbal object has participated in Agree. The first hint is the case marking on the verbal object; recall that object case is elsewhere conditioned on object agreement in Nez Perce. And strikingly, just as for a typical object, if the underlying object is indefinite, it may be an antipassive object and lose case (the causee argument in (68) is pro):

(68) 'e-sepée-q'uyim-se tewlíikt.

3OBJ-CAUSE-climb-IMPERF tree

I make him climb a tree. (Crook, 1999, 179)
Harold-nim pée-sepe-wemsi-se
sík'em Lini-ne.
H-ERG 3/3-CAUSE-borrow-IMPERF horse L-OBJ
Harold is having Lindy borrow a horse (lending a horse to Lindy).

We have seen above that the correlation between caselessness and indefiniteness in Nez Perce is due to the inability of property-type objects to agree, supporting the contention that object agreement targets the underlying object in causative constructions. Moreover, just as in a non-causative, if the causee binds the possessor of the underlying object, the underlying object must be caseless:

a. Payton-ne pée-sepe-tim'in-e we'níkt. P-OBJ 3/3-CAUSE-write-PERF name

She made Payton $_{i}$ write his $i$ name.

b. Payton-ne pée-sepe-tim'in-e we'nikí-ne.

P-OBJ 3/3-CAUSE-write-PERF name-OBJ

She made Payton write a/the name.

Comment: "if you say we'nikine, it's just a name, not his name."

Thus we find the equivalent of both antipassive and extended reflexive constructions in causatives. If the conditions on object caselessness are linked to object agreement, as I have argued above, this pattern strongly suggests object agreement with the underlying object in a causative construction. An Agree relation obtains, but no agreement is spelled-out: why? The reasons for the non-expression of this object agreement may be templatic; they may be due to the potential intervention of the lower 
object agreement between the verb and derivational morphology (the causative); or, as Henry Davis suggests, they may derive from a haplological or OCP-like process.

Accounting for the possibility of two agreement heads, and two agents, in Nez Perce causatives, I adopt a structure as follows:

(71) Structure of causativized transitives

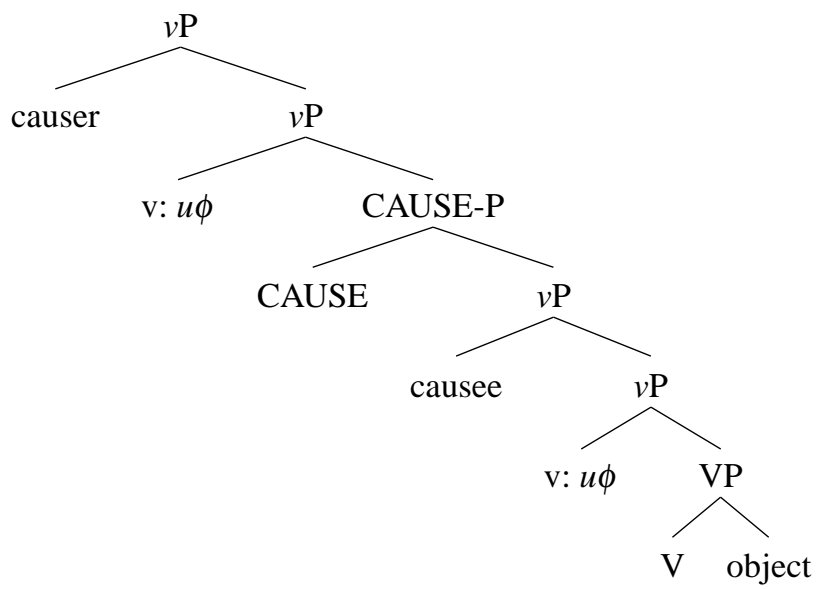

This structure follows Parsons (1990), Pylkkänen (2002), Kratzer (2005) and others in positing a head CAUSE that introduces a causing event, not a causer individual; the causer argument is introduced by agent-introducing $v$ above CAUSE. The structure below CAUSE contains a complete argument-structural projection for the verb. Accordingly, object agreement is present on the highest head of the verb's projection. Object agreement is also present on the higher $v$ head, the highest head of the overall argument-structural projection for the causative construction. The higher agreement head is realized morphologically while the lower one is not, though we can diagnose its presence via patterns of case-marking on the underlying object.

Given that the underlying object is an agreeing object in cases like (67) and (70b), the lower $v \mathrm{P}$ will end up with fully valued $\phi$-features. The Agreeing $v$ Hypothesis leads us to expect that ergative case would be assigned to the specifier of this lower $v \mathrm{P}$, therefore. If ergative case is assigned to any argument in the specifier of a $v$ head with fully valued $\phi$-features, the causee argument in transitive causatives should receive ergative case. But this is impossible. The causee argument must receive objective case.

The consequence is that we cannot define subjecthood purely argument-structurally, at least so far as ergative case is concerned. The relevant conception of transitive subject must make reference to the higher functional structure often taken to define subjecthood, i.e. T (or whatever other head is responsible for subject agreement, e.g. I/AgrS) ${ }^{50}$ We can then generalize the following condition on Nez Perce ergative

\footnotetext{
50 A reviewer suggests that the Agreeing $v$ Hypothesis may be still be tenable if ergative is due to a $v$ head which must be selected for by agreeing T. Note, however, that this selection would have to operate at a distance, as $v$ and $\mathrm{T}$ may be separated by aspect, space marking (see Deal Forthcoming) and potentially adverb-related projections as well.
} 
case, the distillation of what it means for ergative to target transitive subjects in this language: 5152

(72) Transitive subject condition on Nez Perce ergative:

The ergative case is realized on the nominal agreeing with $\mathrm{T}$ just in case it originates in a $v \mathrm{P}$ whose head has fully-valued $\phi$-features.

Condition (72) expresses the core transitivity fact uncovered in section 3: the transitive clause is the clause with successful object agreement. It also expresses the fact uncovered in this section that subjecthood cannot be defined purely argumentstructurally, at the risk of predicting ergative case on causee arguments. Further, these two aspects of the generalization are tied together via the $v \mathrm{P}$ layer in which the subject originates.

The generalization established, the following section offers a look at how a theory of Nez Perce case may be implemented such that condition (72) is captured. We will see that it is possible to capture Nez Perce case marking without flavors of $v$ (i.e. $v$ heads that differ syntactically but not semantically), a stipulated connection between ergative and object agreement, or indeed any syntactic primitive 'ergative case', simplifying the commitments of the Agreeing $v$ theory while at the same time improving its empirical coverage.

\section{Ergative as subject and object agreement}

What is ergative case, that it should be constrained by both subject and object agreement?

It is clear from our discussion of caselessness that neither subject case nor object case is correlated with syntactic licensing in Nez Perce (see also Marantz 1991). Subjects appear without case at the whim of objects. Objects appear without case when a structurally superior object claims the sole object case-marker (e.g. the theme yields the case-marker to the goal in a ditransitive) and when they cannot agree (as in antipassives and extended reflexives). If one is committed to an abstract Case theory regulating the licensing of nominals, one is left to conclude that abstract Case does not correlate with morphological case in Nez Perce. Notably, morphological case has to do with agreement, whereas abstract Case qua licensing is independent of agreement. $^{53}$

That the ergative case is not an abstract Case popularly construed still leaves open whether it is assigned (in whatever sense) in the syntax or in the morphology. 54

\footnotetext{
51 This generalization abstracts away from cases like (64) where the subject is an undergoer. On these, see note 58 .

52 Stepping away from the Agreeing $v$ hypothesis, we are no longer forced to posit multiple syntaxes ("flavors") for external-argument introducing $v$ in Nez Perce. The semantics of introducing an agent need correspond only to a single syntactic encoding: $[\mathrm{u} \phi]$ features are always present on that $v$ that introduces external arguments in Nez Perce. When they fail to obtain a value via agreement, they are discarded by the morphology.

53 On this latter point, see also Davis and Matthewson (2003).

54 This dichotomy presupposes a view of grammar where syntactic and morphological components or processes are distinguished. Among scholars granting this distinction, the morphological view here is at
} 
I pursue a morphological account here for a number of reasons. First, it does not appear that ergative and objective case-markers are semantically interpreted in Nez Perce; they do not correlate with agency or aktionsart, as subject and object casemarkers in various languages have sometimes been claimed to do (on the former, see section 4.1; on the latter, Kiparsky 1998, Kratzer 2004). Thus, if case information were present in the syntax, it would be entirely uninterpretable at LF - both on the assigner and on the recipient. A principle like Full Interpretation (Chomsky, 1995) militates against the inclusion of such features in the syntax.

Second, the dependency of subject case on object agreement is unexpected if case and agreement are checked/valued for subject and object in familiar ways, i.e. through separate mechanisms for subject and for object. Standard assumptions hold the T/I/AgrS head responsible for both subject case and agreement, and a lower $v / \mu /$ AgrO head responsible for both object case and agreement (i.a. Johnson 1991); whatever specific labels and assumptions one adopts, it is not obvious how the two syntactic systems can be related to each other while preserving the syntactic function for which they were intended. But explaining the dependency of ergative case on object agreement in Nez Perce calls for just this sort of link. We should thus not take it to be a "cheap" or default position to locate the ergative case within the syntactic component. Rather, it introduces a notable point of variation into this system: sometimes the subject's case feature is valued by $\mathrm{T}$, and sometimes other considerations are necessary.

The final reason for pursuing a morphological account is that it allows us to adopt a kind of reductionism about ergative, and indeed about case in general. Using the tools made available by a Distributed Morphology-style morphology, such as I pursue here, we are able to dispense entirely with the primitive 'ergative case' in favor of a combination of independently motivated syntactic features. These features are manipulated by the syntax and interpreted by the morphology. One way that the morphology can interpret features resulting from agreement, for instance, is as nominal case. Nominal case is related to verbal agreement because case is just a form of spell-out of agreement. ${ }^{55} \mathrm{We}$ do not need to accord cases the status of theoretical primitives. I take this to be an important theoretical virtue.

The crucial steps for the implementation here are syntactic agreement and late insertion. Unlike so-called "Case features", the features involved in agreement are interpretable on the nominal from which they originate, avoiding the Full Interpretation problem outlined for Case above. What I will try to do here is let the "syntaxiness" of case-marking fall out of its dependence on a fully syntactic system of agreement. This emerges via a theory of the architecture of the morphological interface which assumes late insertion, here Distributed Morphology (Halle and Marantz 1993, Harley and Noyer 1999). In this model, the syntax manipulates abstract feature bundles which are realized in the morphological component with Vocabulary Items, i.e. pairs of phonological features and morphosyntactic features. Vocabulary

present the minority position; a recent defense of the morphological position can be found in McFadden (2004).

55 This approach has also been pursued by Platzack (2006), though the present proposal was developed independently. Platzack proposes that several difficult case paradigms in Icelandic can be accounted for by treating case as the spell out of agreement. Related ideas can also be found in Haeberli (2001, 300-301). 
Item compete for insertion at a syntactic node, and the item that matches the greatest number of the node's features without conflicting or overspecifying is inserted.

We begin with the agreeing object. Recall that the object bears case only if it agrees. This means the morphology must have access to whether or not a nominal has agreed. We can capture this by supposing that agreement in the syntax is essentially the establishment of a sharing relation between $\phi$-features. Those nominals and agreement heads that have agreed in the syntax are passed to the morphology with shared $\phi$-features. To make sure that nominals agreeing with $v$ can be marked differently from those agreeing with $\mathrm{T}$, we must allow that nominals which have agreed are passed to the morphology with an indication of which head they have agreed with. I indicate this here by annotating the agreeing $\phi$-bundle with the category of its agreement source. ${ }^{56} \mathrm{I}$ indicate sharing of $\phi$ features by coindexation.

a. Before agreement

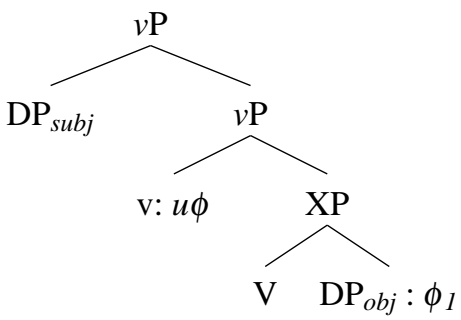

b. After agreement

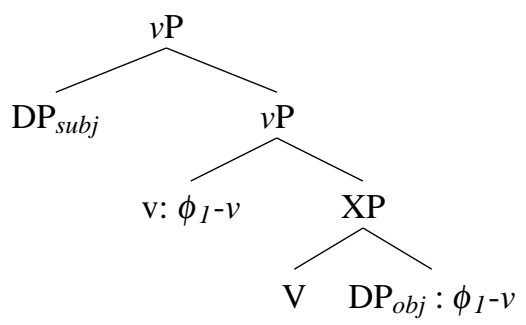

The morphology interprets the structure in (73bb) in two ways: it spells-out the $\phi$ features on $v$, resulting in object agreement, and it marks the DP by assigning it a case-marker. The objective case-marker is inserted as the spell out of a $\phi$-bundle annotated $v$ on a D head; ${ }^{57}$ the object agreement markers spell out $\phi$-features annotated $v$ otherwise.

\section{(74) Vocabulary Item for objective case marker $[\phi-v],[\mathrm{D}]$ Phonology: /ne/}

\footnotetext{
56 This system produced is in a sense notationally similar to the approach pursued by Pesetsky and Torrego (2007), in that when T agrees with a nominal, the nominal's $\phi$ bundle is annotated T, and the spell-out of this annotation may concern case. However, my system differs from Pesetsky and Torrego's in that I do not take it that case is established in the syntax, and thus do not equate the $\mathrm{T}$ annotation with case or link it to licensing.

57 The [D] feature here serves the same role as McFadden (2004)'s [+case] feature, viz to distinguish a dependent-marker (case) from a head-marker (agreement).
} 
(75) Sample Vocabulary Item for object agreement: plural

$[\mathrm{pl}-\mathrm{v}]$

Phonology: /nees/

A non-agreeing object, in virtue of not having received the $v$ annotation via agreement, will not be a candidate for insertion of the objective case marker. This is because the objective case-marker Vocabulary Item is overspecified for the realization of a $\phi$-bundle which is simply unannotated $[\phi]$. I assume that morphemes may only spell out features that belong to the nodes they realize (Halle and Marantz 1993). The objective case-marker, if asked to spell out a non-agreeing object's $\phi$-bundle, would spell out $\phi$-features in addition to an annotation $v$ not present in the input, a result that is barred.

We turn next to the mechanisms of subject agreement. Following the conventions above, we can establish a structure like (76) for the transitive clause subsequent to agreement.

(76) After agreement in the transitive clause (first take)

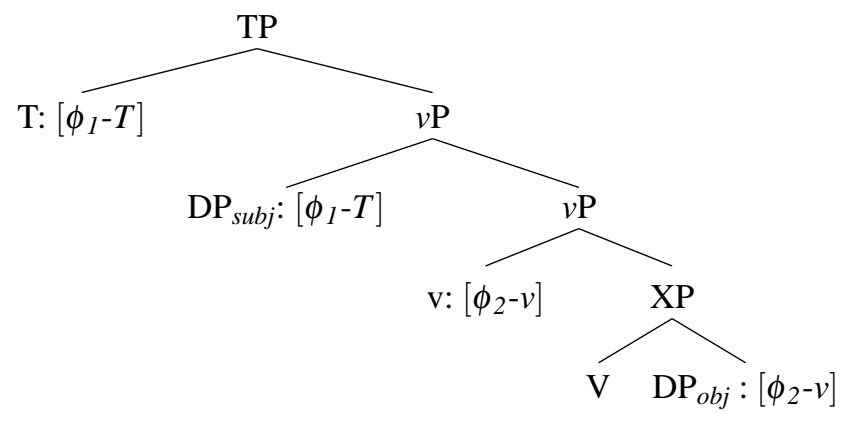

This structure brings us quite close to the generalization in (72). We can now capture the subject as that nominal with a $[\phi-T]$ bundle, and the transitive subject as that nominal with $[\phi-T]$ that occupies the specifier of a head marked $[\phi-v]$, i.e. the head marked with the features of the object attained via agreement.

Now, as things stand in (76), the transitive subject is defined in part featurally (via its $[\phi-T]$ bundle) and in part configurationally (i.e. it must reside in the Spec of a particular kind of head). This differs from the transitive object, which we saw above can be defined purely featurally, via its $[\phi-v]$ feature. It was in virtue of the purely featural definition of transitive object that we were able to formulate the object case Vocabulary Item as in (74). Like other material inserted in the morphological component, the objective case marker is chosen for insertion based on feature matching between the syntactic node to be realized and the morphological material available in the language (Halle and Marantz, 1993). It seems, then, advantageous to pursue a purely featural definition of transitive subject as well.

Only one further detail is necessary to make the category of transitive subject one that can be singled out featurally by the morphological component: we must allow that the agreement marker on $v$ be passed to the specifier of $v \mathrm{P}$. Some precedent for doing so comes from the literature on so-called inherent case, i.e. that nominal marking that is directly correlated with thematic information (Woolford, 1997, i.a.). 
An inherent case-marked nominal receives its marking in virtue of the argumentstructural position in which it originates. This means that there must be a means of in situ feature-sharing between specifier and head positions within the argument structural projection, such that the specifier nominal may be appropriately marked by the argument-structural head - that is, there must be made available some form of in situ Spec-head agreement. While there has been contention over the instances in which cases should be analyzed as theta-related (including some earlier in this very paper), it is accepted that thematic information can play a role in case-marking at least in some languages, some of the time; we should note, then, that the possibility of Spec-head agreement makes a link between case and thematic information at least possible. And if Spec-head agreement is to be countenanced in inherent case systems, the simplest explanation is that it is in fact generally available. This allows us to explain the relevance of object agreement for the subject nominal: the agreement feature that the $v$ head obtains from the object is shared with the subject. ${ }^{58}$

After agreement in the transitive clause (final take)

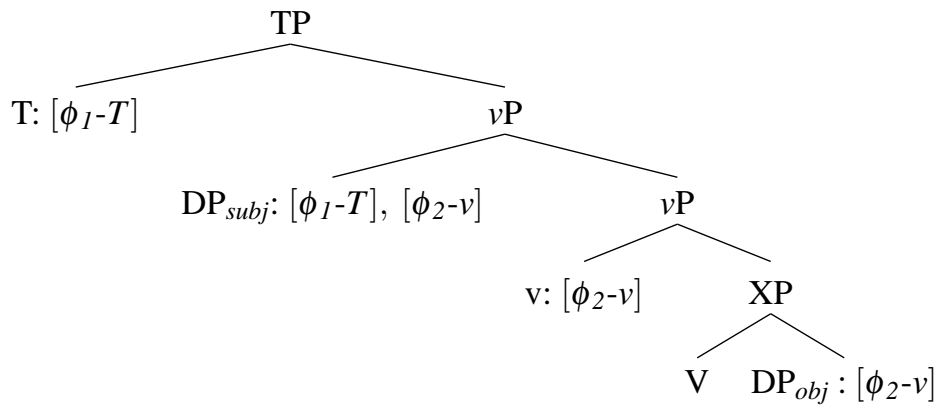

We can now give a featural definition of the transitive subject, and accordingly, a vocabulary entry for the ergative case morpheme:

(78) Vocabulary Item for ergative case marker:

$[\phi-T],[\phi-v],[\mathrm{D}]$

Phonology: /nm/

This Vocabulary Item can only be inserted on a nominal that has received agreement features from both $\mathrm{T}$ and $v$ : the transitive subject.

\footnotetext{
58 In a case like (64) where the subject is an undergoer, it plausibly obtains a position in the specifier of $v \mathrm{P}$ by movement. I surmise that this movement is motivated by a need to move to the edge of the $v \mathrm{P}$ phase and accordingly is driven by Agree/agreement with $v \mathrm{P}$. On this proposal the subject of (64) agrees with both $v$ and $\mathrm{T}$ under c-command. (I take it that our theory should not generally bar multiple heads from agreeing with the same goal in this way; see Deal (to appear).) Henry Davis suggests that, alternatively, what we could be seeing in these facts is a requirement that all agreement processes that underlie case morphology take place in a Spec-head configuration. On this account, the subject would agree with $v$ from the specifier position of $v \mathrm{P}$ and subsequently move to the specifier position of TP. Note that the vocabulary entry for ergative case is appropriately neutral on how the subject comes to obtain both T- and $v$-marked features.
} 


\section{Sahaptin}

An interesting twist on the Nez Perce pattern is found in Sahaptin, a family of dialects closely related to Nez Perce (but not mutually intelligible with it). In Sahaptin, the presence of an ergative case marker on the subject is dependent on the person features of both subject and object. The two languages differ in the precise vocabulary item for the ergative case marker, but the mechanism by which the grammar produces ergativity is the same.

Our formalization of the transitivity condition on Nez Perce ergative leads us to predict the possibility of languages where the form or presence of an ergative case marker is sensitive to the grammatical features of the object, not just the mere fact that the object agrees. Sahaptin is precisely such a language: in Sahaptin, ergative case is only expressed on a 3rd person singular subject in the presence of a 1st or 2nd person object. (Note that the object is pro in (80). Its person information is easily recoverable via the second position clitic; however, this clitic does not express distinctions of (ase. $)^{59}$

(79) i-tux̂ná-na=aš wínš-nim (ína).

3SUBJ-shoot-ASP=1SG man-ERG 1SG.ACC

The man shot me. (Rude, 1985, 144)

(80) iwínš-nim=naš i-q'ínun-a.

man-ERG $=1$ SG 3 SUBJ-see-PAST

The man saw me. (Rude, 1997, ex 25)

(81) $\mathrm{x}^{\mathrm{w}}$ isaat-nim=naš i-ní-ya ináy k'úsi.

old.man-ERG=1SG 3SUBJ-give-PAST 1SG.ACC horse

The old man gave me a horse. (Rigsby and Rude, 1996, 674)

A third person subject with a third person object takes no ergative marking. In the following cases both transitive (82) and intransitive (83) clauses show the same verbal agreement and form of the subject, despite the presence of an accusative object in (82).

(82) iwínš i-q'ínun-a miyánaš-na.

man 3SUBJ-see-PAST child-ACC

The man saw the child. (Rude, 1997, ex 26)

(83) i-wiyánawi-ya iwínš.

3SUBJ-arrive-PAST man

The man arrived. (Rude, 1997, ex 2)

\footnotetext{
${ }^{59}$ In Sahaptin examples I provide the name of the Sahaptin dialect if provided by the source. Some slight dialect differences are seen in the data below, e.g. the varying form of 'man' in (79) versus the other examples; following Rude (1997) and Rigsby and Rude (1996), I assume that Sahaptin dialects behave alike in the phenomena discussed here.

Abbreviations in Sahaptin glosses are 3SUBJ 3rd person subject agreement, 3OBJ 3rd person object agreement, ASP aspect, IMPERF imperfective aspect, APPL applicative, ERG ergative case, ACC accusative case.
} 
This pattern can be explained if we suppose that object agreement in Sahaptin proceeds just as it does in Nez Perce. Just like in Nez Perce, 1st/2nd person object agreement is not phonologically overt. Furthermore, in the presence of 3rd person subject agreement, 3rd person object agreement is not overt in Sahaptin either (thus with Sahaptin (82) cf. Nez Perce pé-ex-ne, 3/3-see-PERF, 'He saw him'). Object agreement is in fact only overt if the object is 3rd person and the subject is $1 \mathrm{st} / 2$ nd person. There is also no object number agreement in Sahaptin.

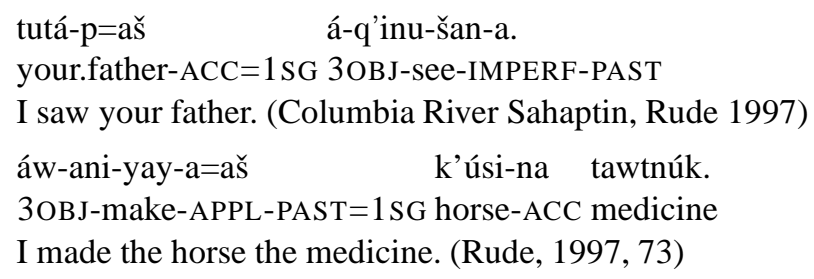

This small amount of overt agreement provides some independent reason to postulate object agreement in Sahaptin, as in Nez Perce; $v$ agrees with the object nominal. Again as in Nez Perce, the object agreement features are passed from $v$ to the subject nominal, and thus once this nominal has participated in subject agreement, it has access to both $[\phi-T]$ and $[\phi-v]$ features. The crucial difference is that in Sahaptin it matters exactly what the features inherited from the object via object agreement are. The ergative case marker is inserted only if the object features are 1st or 2nd person. This means we can give a vocabulary item for the Sahaptin ergative as follows:

(86) Vocabulary Item for Sahaptin ergative case marker:

[3sg-T], [+participant- $v]$

Phonology:/nim/

Here [+participant] may be taken as a feature that subsumes 1st and 2nd person, as in Harley and Ritter (2002); or (86) may be taken as an abbreviation for two vocabulary items, one in terms of a referential feature [1st] and one in terms of a referential feature [2nd], in line with the proposal by Kratzer (to appear).

\section{Conclusions}

The investigation in this paper leads to conclusions for both the study of ergativity in Nez Perce and the general study of morphological ergativity.

On the former count, we have seen that an adequate theory of case, caselessness and especially ergativity in Nez Perce must be closely concerned with agreement of both object and subject. The transitive subject, the category widely acknowledged to be the target of ergative case, cannot be reduced to (transitive) agent, nor to the subject of a clause containing a theme or goal argument; it must instead be understood as the agreeing subject of a clause with an agreeing object. To see this, we have delved deeply into the origins of caselessness in Nez Perce, concluding that caseless clauses are heterogeneous syntactically and semantically. One class of caseless clauses requires an antipassive analysis. Objects in this type of clause are property-denoting 
NPs, not referential DPs; due to its "smallness", the antipassive object cannot agree, and accordingly does not bear case. By contrast, extended reflexive objects are full, referential DPs. However, agreement in such clauses has to target a bound variable possessor which lacks $\phi$-features. Similarly to Italian, Nez Perce responds to the difficulties of such agreement by simply showing no object agreement in extended reflexive clauses. Concomitantly, ergative case-marking is not possible.

We saw further that in order to incorporate object agreement into a formalization of the category of transitive subject, we must formalize 'subject' in a way that makes reference to subject agreement. Failing this we will make the wrong predictions in causatives. This definition of subject allows us to view the transitive subject as that category uniquely positioned to receive agreement information from both high (T) and low $(v)$ sources, shedding light on its special treatment across languages. Our analysis in terms of morphological case allowed us to capture the dependency of case on syntactic factors by linking it to agreement processes that operate over syntactic structures. It allowed us to pursue an analysis of ergative as a kind of portmanteau spell-out of subject agreement and object agreement in combination with a nominal, allowing us to dissolve Nez Perce ergativity into a combination of independently motivated pieces of grammar.

Extending the study beyond the Nez Perce facts, we saw how the present view might account for the dependency of ergative case on object person in Sahaptin. ${ }^{60}$ How widely the precise analysis offered for these languages may be extended in pursuit of a universal theory of ergativity will depend on how syntactically and morphologically unified "ergative languages" are. Comparative work on ergativity begins in earnest once we have established the ways in which languages do and do not make use of identical means in singling out transitive subjects. Where the relevant criteria of subjecthood and transitivity in Nez Perce concern participation in the syntactic process of agreement, it is clearly logically possible that other languages may substitute alternative criteria. Yet it is also possible that languages might make use of the Nez Perce system without wearing it on their sleeve, for instance by coupling the case-agreement connection with a general reluctance to spell out one or the other end of the relation. We saw in the discussion of causatives that Nez Perce agreement is not spelled out under certain conditions; a language with ergative case but no morphological object agreement could be analyzed as a more consistent system along these lines. Where in Nez Perce a morphological agreement system makes the case for case as agreement, in languages with no visible agreement systems we need to look for independent clues of the role of agreement in determining case patterns. The discussion of anaphor agreement effects suggests that such effects might serve as a promising laboratory for the diagnosis of syntactic agreement that goes without general morphological expression.

\footnotetext{
60 The analysis is also extended to Warlpiri in Deal (2008a).
} 


\section{Appendix: Reflexives}

The typical reflexive construction in Nez Perce involves a reflexive prefix that replaces subject and object agreement prefixes.

a. 'e-téwyek-se. 3OBJ-feel-IMPERF

I feel it, I sense it.
3/3-pity-PERF

$\mathrm{He}_{i}$ pitied $\operatorname{him}_{j}$. b. ta'c 'inée-tewyek-se. good 1SG.REFL-feel-IMPERF I feel good.

b. 'ipnée-yyew-ne. 3SG.REFL-pity-PERF He pitied himself.

Woolford $(1999,267)$ analyzes the Nez Perce reflexive markers as a "a special anaphoric form of agreement" that obtains when a probe agrees with an anaphor. If this were so, we would expect reflexive prefixes to show up in extended reflexives, if indeed object agreement targets an anaphor in such cases. I will show briefly that this is not the correct analysis of reflexive prefixes, and that their absence in extended reflexives is not a problem for my analysis.

Reflexive morphology in Nez Perce is derivational. Unlike object agreement for person and number, reflexive prefixes are found in nominalizations:
a. 'inaa-tamapayk-t
1SG.REFL-report.on-PART
testimony (of myself)
b. 'ipnée-ku-t'es
3SG.REFL-get.water-PART
cup, mug
c. 'ipnee-wle-ke'yk-e'í
3SG.REFL-run-go-NMLZR
car

Reflexive morphology also sometimes combines with verbs in non-compositional ways, both in forming idioms (special meanings given independently motivated parts) and in changing argument structure. An example of the former is the reflexive form of the verb hinaq' $i$ 'to finish, complete', which means 'to prepare, to get ready' (Aoki, 1994, 137).

(90) 'áayat 'ipnáa-hiinaq'i-s.

woman 3REFL-finish-PCT

The woman is ready.

Comment: "She's all set, prepared from head to toe, ready to go out"

(91) 'áayat-om páa-hinaq'i-s haacwal-a.

woman-ERG 3/3-finish-PCT boy-OBJ

The woman finished (with) the boy.

NOT: The woman got the boy ready.

Comment: "She's finished with that guy." 
An example of the reflexive changing the argument structure of a verb concerns the verb kuи 'get water'. This verb is only intransitive (unergative). However, the reflexive combines with the bare verb to give the meaning 'drink'.

(92) teqe-kúu-se.

quickly-get.water-IMPERF

I am going to get water briefly. (Aoki, 1994, 249)

(93) 'inée-kuu-se.

1SG.REFL-?-IMPERF

I am drinking.

If the reflexive prefix in a case like (93) were a special form of agreement marking an anaphor object, we would need to posit a transitive verb root kuu with which the reflexive combines and of which the anaphor is the object. Yet this transitive verb root is not otherwise attested, and indeed, it is not clear what it would mean. The simpler analysis is that this is a case where derivational morphology has fused to a verb stem to the point where compositional analysis is no longer possible. Such fusion does not target the inflectional morphology of Nez Perce, such as the subject and object agreement markers shown in Table 2. For this reason, it does not seem plausible that reflexive prefixes in Nez Perce are a form of object agreement.

I analyze the reflexive prefixes as derivational, detransitivizing morphology. In a case where the reflexive does combine compositionally with independent material, it combines with an unsaturated predicate and intersects it with a predicate that provides a theta-role to the subject, i.e. $v$. This is shown in the following tree, provided with step-by-step semantic interpretations, for the Nez Perce equivalent of 'Coyote pitied himself'. The overall $v \mathrm{P}$ is a property of an events that holds of an event of pitying Coyote whose agent is Coyote-i.e. an event of self-pitying by Coyote. ${ }^{61}$

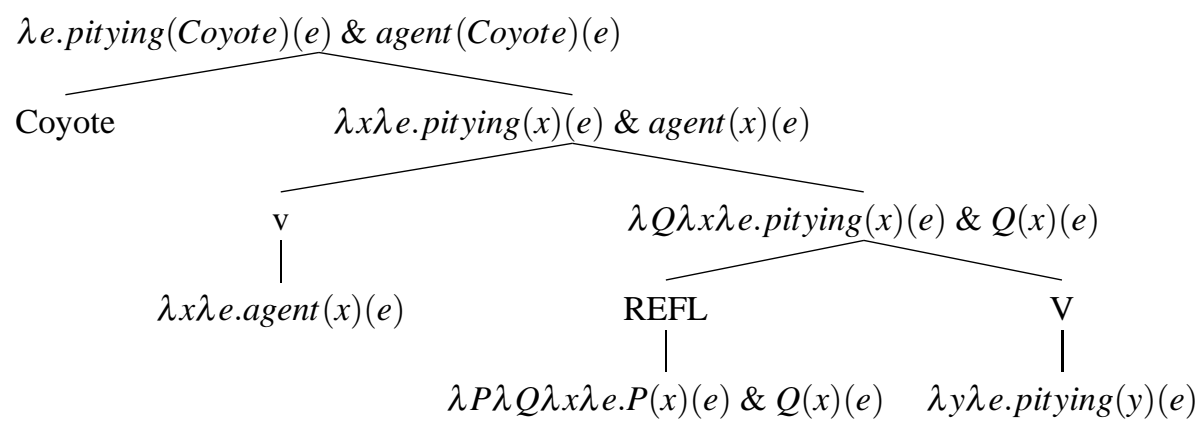

The reflexive prefixes are not found in extended reflexives because in these cases there is no detransitivization (in the sense of unsaturated argument positions available to REFL). In the standard case the object saturates the object position of the verb; this

\footnotetext{
61 The denotation given for REFL is simply a function which intersects the meaning of the verb with the meaning of $v$. We might wonder if we could do without any REFL morpheme in the syntax and have the reflexive morphology just spell-out the intersective mode of composition between the verb root and the $v$ head (on the spell-out of modes of composition, see Chung and Ladusaw 2004); I am not sure how such an analysis would be able to deal with cases like (93).
} 
position cannot be bound off by REFL. If the possessor could move to the specifier of APPL, this position could not be bound off by REFL; it would be saturated by the possessor. In this way, the detransitivizing semantics of the reflexive morpheme prohibit its application to the extended reflexive construction.

Acknowledgements I am grateful to my Nez Perce teachers Bessie Scott, Florene Davis and Cecil Carter for sharing their language with me. Unattributed judgments reported here are due to these kind elders. This research was funded by the National Science Foundation under Grant No. BCS-0418311 to Barbara H. Partee and Vladimir Borschev, under a Graduate Research Fellowship, and under Dissertation Improvement grant BCS-0843905, as well as by the American Philosophical Society via a Phillips Fund grant. Thanks to Rajesh Bhatt, Harold Crook, Henry Davis, Angelika Kratzer, Cathy O'Connor, Barbara Partee, Ellen Woolford, an anonymous reviewer, and audiences at UMass, MIT, the CUNY Graduate Center, UC San Diego, Stanford, Harvard and LSA 2008 for helpful feedback.

\section{References}

Aissen, Judith. 1999. Agent focus and inverse in Tzotzil. Language 75:451-485.

Aldridge, Edith. 2004. Ergativity and word order in Austronesian languages. Doctoral Dissertation, Cornell.

Anand, Pranav, and Andrew Nevins. 2006. The locus of ergative case assignment: evidence from scope. In Ergativity: emerging issues, ed. A. Johns, D. Massam, and J. Ndayiragije. Springer.

Aoki, Haruo. 1970. Nez Perce grammar. University of California Publications in Linguistics. Berkeley: University of California Press.

Aoki, Haruo. 1979. Nez Perce texts. Berkeley: University of California Press.

Aoki, Haruo. 1994. Nez Perce dictionary. Berkeley: University of California Press.

Aoki, Haruo, and Deward Walker. 1989. Nez Perce oral narratives. University of California Press.

Baker, Mark. 1988. Incorporation: a theory of grammatical function changing. Chicago: University of Chicago Press.

Bandhu, Churamani. 1973. Clause patterns in Nepali. In Clause, sentence and discourse patterns in selected languages of Nepal, ed. Austin Hale, volume 2, 1-79. Norman: SIL.

Bittner, Maria. 1987. On the semantics of the Greenlandic antipassive and related constructions. International Journal of American Linguistics 53:194-231.

Bittner, Maria. 1994. Case, scope and binding. Dordrecht: Kluwer.

Bittner, Maria, and Ken Hale. 1996. The structural determination of case and agreement. Linguistic Inquiry 27:1-68.

Blake, Barry J. 1987. Australian aboriginal grammar. London: Croom Helm.

Bobaljik, Jonathan David. 2005. Where's phi? In Leiden Papers in Linguistics, ed. Marjo van Koppen.

Borer, Hagit. 2005. In name only. Oxford University Press.

Bowers, John. 1993. The syntax of predication. Linguistic Inquiry 24:591-656.

Bowers, John. 2002. Transitivity. Linguistic Inquiry 33:183-234.

Breen, JG. 1976. Wangkumara. In Grammatical categories in Australian languages, ed. RMW Dixon, 336-339. Canberra: Australian Institute of Aboriginal Studies. 
Breen, JG. 1981. Margany and Gunya. In Handbook of Australian languages, ed. RMW Dixon and Barry J Blake, volume 2, 274-394. John Benjamins.

Bruening, Benjamin. 2007. On the diagnostics of structural case and the nature of ergative case: a reply to Woolford 2006. University of Delaware.

Carnie, Andrew, and Phillip Cash Cash. 2006. Tree-geometric relational hierarchies and Nuumiipuutímt (Nez Perce) case. In Ergativity, ed. A. Johns, D. Massam, and J. Ndayiragije, 229-244. Springer.

Chomsky, Noam. 1981. Lectures on government and binding. Dordrecht, The Netherlands: Foris Publications.

Chomsky, Noam. 1995. The minimalist program. Cambridge, Massachusetts: MIT Press.

Chung, Sandra, and William A. Ladusaw. 2004. Restriction and saturation. Cambridge, MA: MIT Press.

Cinque, Guglielmo. 1999. Adverbs and functional heads: a cross-linguistic perspective. New York: Oxford University Press.

Comrie, Bernard. 1978. Ergativity. In Syntactic typology: studies in the phenomenology of language, ed. W. P. Lehman, 329-394. University of Texas Pres.

Crook, Harold David. 1999. The phonology and morphology of Nez Perce stress. Doctoral Dissertation, University of California at Los Angeles.

Das Gupta, Kamalesh. 1971. An introduction to the Nocte language. North-East Frontier Agency.

Davis, Henry, and Lisa Matthewson. 2003. Quasi objects in St'át'imcets: on the (semi-)independence of agreement and Case. In Formal approaches to function in grammar in honor of Eloise Jelinek, ed. H. Harley A. Carnie and M. Willie, 79-106. Amsterdam/Philadephia: John Benjamins.

Dayal, Veneeta. 2003. A semantics for pseudo-incorporation. Semantics Archive.

Deal, Amy Rose. 2007. Antipassive and indefinite objects in Nez Perce. In Proceedings of SULA 4, ed. A.R. Deal, 35-47. Amherst: GLSA.

Deal, Amy Rose. 2008a. Ergative and applicative in Warlpiri. University of Massachusetts.

Deal, Amy Rose. 2008b. Property-type objects and modal embedding. In Proceedings of Sinn und Bedeutung 12, ed. Atle Grønn. Oslo: ILOS 2008.

Deal, Amy Rose. Forthcoming. Events in space. In Proceedings of SALT 18, ed. T. Friedman and S. Ito. Cornell: CLC Publications.

Deal, Amy Rose. to appear. On the origin and content of expletives: evidence from "selection". Syntax.

Déchaine, Rose-Marie, and Martina Wiltschko. 2002. Decomposing pronouns. Linguistic Inquiry 33:409-442.

Diesing, Molly. 1992. Indefinites. Cambridge, Massachusetts: MIT Press.

Dixon, R.M.W. 1994. Ergativity. Number 69 in Cambridge Studies in Linguistics. Cambridge University Press.

Dowty, David, and Belinda Brodie. 1984. The semantics of "floated" quantifiers in a transformationless grammar. In Proceedings of WCCFL 3, ed. M.T. Wescoat M. Cobler, S. MacKaye, 75-90. Stanford Linguistics Association.

Farkas, Donka, and Henriëtte de Swart. 2003. The semantics of incorporation. Stanford, CA: CSLI. 
van Geenhoven, Verle. 1998. Semantic incorporation and indefinite descriptions. Stanford, CA: CSLI.

Haeberli, Eric. 2001. Deriving syntactic effects of morphological case by eliminating abstract case. Lingua 111:279-313.

Halle, Morris, and Alec Marantz. 1993. Distributed morphology and the pieces of inflection. In The view from building 20, ed. Kenneth Hale and Samuel Jay Keyser, 111-176. Cambridge, Massachusetts: MIT Press.

Harley, Heidi, and Rolf Noyer. 1999. Distributed morphology. GLOT International 4:3-9.

Harley, Heidi, and Elizabeth Ritter. 2002. Person and number in pronouns: a featuregeometric analysis. Language 78:482-526.

Heim, Irene, and Angelika Kratzer. 1998. Semantics in generative grammar. Malden, MA: Blackwell.

Hockett, Charles. 1958. A course in modern linguistics. New York: Macmillan Company.

Holmer, Nils M. 1963. On the history and structure of the Australian languages. Lund: Lundequistska Bokhandeln.

Johnson, Kyle. 1991. Object positions. Natural Language and Linguistic Theory 9:577-636.

Kayne, Richard S. 1994. The antisymmetry of syntax. Cambridge, Massachusetts: M.I.T. Press.

Kiparsky, Paul. 1998. Partitive case and aspect. In The projection of arguments, ed. M. Butt and W. Geuder, 265-307. Stanford: CSLI.

Kratzer, Angelika. 1996. Severing the external argument from its verb. In Phrase structure and the lexicon, ed. Johan Rooryck and Laurie Zaring, 109-137. Dordrecht, The Netherlands: Kluwer Academic Publishers.

Kratzer, Angelika. 1998. More structural analogies between pronouns and tenses. In Proceedings of SALT VIII. CLC Publications.

Kratzer, Angelika. 2003. The event argument and the semantics of verbs. To appear, MIT Press.

Kratzer, Angelika. 2004. Telicity and the meaning of objective case. In The syntax of time, ed. J. Guéron \& J. Lecarme. Cambridge, MA: MIT Press.

Kratzer, Angelika. 2005. Building resultatives. In Event arguments: foundations and applications, ed. C. Maienborn \& A. Wöllstein, 177-212. Tübingen: Max Niemeyer Verlag.

Kratzer, Angelika. to appear. Making a pronoun: Fake indexicals as windows into the properties of pronouns. Linguistic Inquiry .

Kruspe, Nicole. 2004. A grammar of Semelai. Cambridge University Press.

Legate, Julie Anne. 2002. Warlpiri: theoretical implications. Doctoral Dissertation, MIT.

Legate, Julie Anne. 2006. Split absolutive. In Ergativity: emerging issues, ed. Alana Johns, Diane Massam, and Juvenal Ndayiragije, 143-172.

Legate, Julie Anne. 2008. Morphological and abstract case. Linguistic Inquiry 39:55101.

Marantz, Alec. 1984. On the nature of grammatical relations. Cambridge, Massachusetts: MIT Press. 
Marantz, Alec. 1991. Case and licensing. In Eastern States Conference on Linguistics, ed. Germán Westphal, Benjamin Ao, and Hee-Rahk Chae, 234-253. University of Maryland, Baltimore: Ohio State University.

McFadden, Thomas. 2004. The position of morphological case in the derivation: a study on the syntax-morphology interface. Doctoral Dissertation, University of Pennsylvania.

Mohanan, Tara. 1995. Wordhood and lexicality: Noun incorporation in Hindi. Natural Language and Linguistic Theory 13:75-134.

O'Connor, M.C. 1992. Topics in Northern Pomo grammar. Outstanding dissertations in linguistics. Garland.

O'Connor, M.C. 2007. External possession and utterance interpretation: a crosslinguistic exploration. Linguistics 45:577-613.

Pandharipande, Rajeshwari. 1997. Marathi. Descriptive Grammar Series. Routledge.

Parsons, Terence. 1990. Events in the semantics of English: A study in subatomic semantics. Cambridge, Massachusetts: MIT Press.

Payne, Doris, and Immanuel Barshi. 1999. External possession: what, where, how, and why. In External possession, ed. Doris Payne and Immanuel Barshi, 3-31. Amsterdam/Philadelphia: John Benjamins.

Pereltsvaig, Asya. 2006. Small nominals. Natural Language and Linguistic Theory 24:433-500.

Pesetsky, David, and Esther Torrego. 2007. The syntax of valuation and the interpretability of features. In Phrasal and clausal architecture: syntactic derivation and interpretation, ed. V. Samiian S. Karimi and W. Wilkins, 262-294. Amsterdam: John Benjamins.

Phinney, Archie. 1934. Nez Percé texts. Columbia University Contributions to Anthropology. Columbia University Press.

Platzack, Christer. 2006. Case as Agree marker. Working Papers in Scandinavian Syntax 77:71-99.

Pylkkänen, Liina. 2002. Introducing arguments. Doctoral Dissertation, MIT.

Rigsby, Bruce, and Noel Rude. 1996. A sketch of Sahaptin, a Sahaptian language. In Handbook of North American Indians, ed. Ives Goddard, volume 17, Languages, 666-692. Washington: Smithsonian Institution.

Ritter, Elizabeth. 1991. Two functional categories in the noun phrase: evidence from Modern Hebrew. In Syntax and semantics 25, ed. Stephen Anderson and Susan D. Rothstein, 37-62.

Rizzi, Luigi. 1990. On the anaphor agreement effect. Rivista di Linguistica 2:27-42.

Rude, Noel. 1985. Studies in Nez Perce grammar and discourse. Doctoral Dissertation, University of Oregon.

Rude, Noel. 1986. Discourse pragmatic context for genitive promotion in Nez Perce. Studies in Language 10:109-136.

Rude, Noel. 1992. Word order and topicality in Nez Perce. In Pragmatics of word order flexibility, ed. D. Payne, 193-208. John Benjamins.

Rude, Noel. 1997. On the history of nominal case in Sahaptian. International Journal of American Linguistics 63:113-143.

Rude, Noel. 1999. External possession in Sahaptian. In External possession, ed. D. Payne and I. Barshi, 403-427. John Benjamins. 
Schwarz, Florian. 2008. Two types of bridging with two types of definites. Presented at Stanford University, February 2008.

Strehlow, T.G.H. 1944. Aranda phonetics and grammar. Number 7 in The Oceania Monographs. Sydney: The Australian National Research Council.

Szabolcsi, Anna. 1987. Functional categories in the noun phrase. In Approaches to Hungarian 2: theories and analses, ed. I. Kenesei, 167-191. Szeged: Jozsef Attila University.

Watters, David E. 1973. Clause patterns in Kham. In Clause, sentence and discourse patterns in selected languages of Nepal, ed. Austin Hale, volume 1, 39-202. Norman: SIL.

Wharram, Douglas. 2003. On the interpretation of (un)certain indefinites in Inuktitut and related languages. Doctoral Dissertation, University of Connecticut.

Woolford, Ellen. 1997. Four-way case systems: Ergative, nominative, objective and accusative. Natural Language and Linguistic Theory 15:181-227.

Woolford, Ellen. 1999. More on the anaphor agreement effect. Linguistic Inquiry 30:257-287.

Woolford, Ellen. 2006. Lexical case, inherent case and argument structure. Linguistic Inquiry 37:111-130.

Wurm, S.A. 1976. Accusative marking in Duungidjawu (Waga-Waga). In Grammatical categories in Australian languages, ed. RMW Dixon, 106-111. Canberra: Australian Institute of Aboriginal Studies.

Yip, Moira, Joan Maling, and Ray Jackendoff. 1987. Case in tiers. Language 63:217250.

Zimmermann, Thomas Ede. 1992. On the proper treatment of opacity in certain verbs. Natural Language Semantics 1:149-180.

Received 28 February 2008

Accepted 22 March 2009 